\title{
Where Have All the Scientific and Academic Freedoms Gone? And What Is ‘Adequate for Science'? The Right to Enjoy the Benefits of Scientific Progress and Its Applications
}

\author{
Klaus D Beiter*
}

Article 15(1)(b) of the International Covenant on Economic, Social and Cultural Rights protects the right of everyone to enjoy the benefits of scientific progress and its applications (REBSPA). While the interpretation of this provision has not really been a focus of attention in the past, this is changing. A danger lies in construing this provision as entitling states to comprehensively regulate the field of science, at the expense of scientific and academic freedom. Scientific or academic freedom, rather than state regulation, guarantees creativity and innovation in the field of science for the benefit of society at large. This article raises four caveats to guide all those tasked with interpreting Article 15(1)(b) - specifically, the UN Committee on Economic, Social and Cultural Rights, right now preparing a General Comment on Article 15(1)(b). Firstly, it is crucial to have conceptual clarity of, and understand the differences between, the REBSPA, freedom of science, academic freedom, freedom of expression, and the right to education. Secondly, science, by its very nature, is not susceptible to being managed. An 'adequate' framework for science should limit state intervention and empower the scientific fraternity. Thirdly, regulation has lately often entailed the adoption of a corporatist approach to science in universities and research institutions. This damages science. Fourthly and finally, UNESCO's recent Recommendation on Science and Scientific Researchers of 2017 constitutes only an imperfect blueprint to guide interpretation of the REBSPA. It fails to address various threats (impact agenda science, peer review, ethical regulation, entrepreneurialisation, accountability excess, absence of rights of participation in governance, and so on) to scientific and academic freedom. Relying throughout on the notion that a science system must be 'adequate for science', the article concludes with a set of 22 recommendations on how the REBSPA should be construed so as to duly respect scientific and academic freedom. The current science regime needs to be fundamentally rethought in the light of such freedom. Otherwise - and many experts concur - we shall soon witness the fatal collapse and disintegration of modern science. Freedom as a pillar of science, and of the REBSPA, is in danger of being lost.

Keywords: Article 15(1)(b), ICESCR, REBSPA, scientific or academic freedom, UNESCO

Principiis obsta (et respice finem)! Resist the beginnings (and consider the end)!

\section{Averting the Collapse of Modern Science}

In his book, Scientific Freedom: The Elixir of Civilization of 2008, Donald Braben remarks that managed science may sound like a good idea. However, he warns that as we do not properly

\footnotetext{
${ }^{*}$ Klaus D Beiter, BIur, LLB (UNISA, Pretoria), Dr iur (LMU Munich); Associate Professor, North-West University (Potchefstroom Campus), Faculty of Law, South Africa; Klaus.Beiter@nwu.ac.za; Affiliated Research Fellow, Max Planck Institute for Innovation and Competition, Munich, Germany. ${ }^{\dagger}$ All quotations from non-English sources in this article were translated into English by the author himself. Sincerest thanks go to various anonymous reviewers for their very valuable comments. Thanks also go to the South African National Research Foundation for having contributed towards funding this research.

${ }^{\dagger}$ The online version of this article has been updated since original publication. A notice detailing the changes has also been published. 
understand creativity, we should refrain from attempting to organise it. We should rather, he underlines, give talented researchers 'the freedom to bring their ideas to fruition'. Article 15(1)(b) of the International Covenant on Economic, Social and Cultural Rights (ICESCR) of $1966^{2}$ protects the right of everyone ' $[\mathrm{t}] \mathrm{l}$ enjoy the benefits of scientific progress and its applications' - linguistically a rather daunting construction, often abbreviated to REBSPA, and sometimes also termed the right to science. If this provision is read with Article 2(1) of the ICESCR - the Covenant's central implementation provision, stipulating that states parties must use maximum available resources towards achieving progressively the full realisation of Covenant rights by all appropriate means ${ }^{3}-$ one is easily tempted to conclude that states parties must take firm control of the science sector, and comprehensively regulate it, to ensure that it will produce benefits for society at large. In the light of Braben's statement, which, as this article will show, by no means reflects an idiosyncratic opinion, the wisdom of such an interpretation should be questioned.

To what extent is it legitimate for governments to regulate science? Furthermore, what is the scope of scientific and academic freedom under Article 15(1)(b)? Wrong answers to these questions are fraught with dangers. In view of the unclear meaning of Article 15(1)(b), Eibe Riedel wonders whether the REBSPA, hitherto one of the more forgotten provisions of the ICESCR, should now form the subject of bold interpretation or whether it should rather be dealt with very cautiously - whether it is a Sleeping Beauty or a sleeping dog that should be left lying. ${ }^{4}$ However, we already live in times of research management, commanded by governments and executed by universities and research institutions. Does this serve society? Ultimately, all too much government commitment in the sphere of science may inhibit the very potential of science that was sought to be promoted by state action in the first place.

For a long time, little consideration was given to the right to science in the work of the Committee on Economic, Social and Cultural Rights, ${ }^{5}$ and it has also essentially been neglected in the academic literature. ${ }^{6}$ This has started to change. Legal commentators have started writing on the subject of the $\operatorname{REBSPA}^{7}$ and the Committee has begun work on a

\footnotetext{
${ }^{1}$ Donald W Braben, Scientific Freedom: The Elixir of Civilization (John Wiley 2008) 89.

${ }^{2}$ International Covenant on Economic, Social and Cultural Rights (1966) (entered into force 3 January 1976) 993 UNTS 3 (ICESCR).

${ }^{3}$ Art 2(1) of the ICESCR states: 'Each State Party to the present Covenant undertakes to take steps, individually and through international assistance and co-operation, especially economic and technical, to the maximum of its available resources, with a view to achieving progressively the full realisation of the rights recognised in the present Covenant by all appropriate means, including particularly the adoption of legislative measures'.

${ }^{4}$ Eibe Riedel, 'Sleeping Beauty or Let Sleeping Dogs Lie? The Right of Everyone to Enjoy the Benefits of Scientific Progress and Its Applications (REBSPA)' in Holger P Hestermeyer and others (eds), Coexistence, Cooperation and Solidarity: Liber Amicorum Rüdiger Wolfrum, Vol 1 (Brill/Nijhoff 2012) 503, 510, 516.

${ }^{5}$ The United Nations Committee on Economic, Social and Cultural Rights is the independent expert body supervising implementation of the ICESCR.

${ }^{6}$ See Ben Saul, David Kinley and Jaqueline Mowbray, 'Article 15: Cultural Rights' in The International Covenant on Economic, Social and Cultural Rights: Commentary, Cases, and Materials (Oxford University Press 2014) $1175,1213-14$ (making this observation).

${ }^{7}$ See Klaus D Beiter, Terence Karran and Kwadwo Appiagyei-Atua, 'Yearning to Belong: Finding a "Home" for the Right to Academic Freedom in the U.N. Human Rights Covenants' (2016) 11 Intercultural Human Rights Law
} 
General Comment. ${ }^{8}$ This is, therefore, an opportune moment to make legal writers, the scientific community, governments, and specifically the Committee aware of the importance of scientific and academic freedom. '[T]he increase and diffusion of knowledge depend entirely upon freedom to search, experiment, criticise, proclaim. Without these freedoms there can be no science'. ${ }^{9}$ To this author it seems that the rage of regulation in science we have been witnessing for some time now (over-incentivisation, setting up managerial hierarchies, enforcing an audit culture, and so on) is destructive of the scientific process itself and thus of the REBSPA. ${ }^{10}$ Should no steps be taken to fundamentally recast current science policy in the light of scientific

Review 107, 164 fn 210, 166-67 fn 216 (where we cite 14 sources addressing the REBSPA). Additionally, the following may be mentioned: Alf Butenschøn Skre and Asbjørn Eide, 'The Human Right to Benefit from Advances in Science and Promotion of Openly Accessible Publications' (2013) 31 Nordic Journal of Human Rights 427; Olivier de Schutter, 'The Right of Everyone to Enjoy the Benefits of Scientific Progress and the Right to Food: From Conflict to Complementarity' (2011) 33 Human Rights Quarterly 304; Brian Gran, Margaret Waltz and Holly Renzhofer, 'A Child's Right to Enjoy Benefits of Scientific Progress and Its Applications' (2013) 21 International Journal of Children's Rights 323; Hans M Haugen, 'Human Rights and Technology: A Conflictual Relationship? Assessing Private Research and the Right to Adequate Food' (2008) 7 Journal of Human Rights 224; Hans M Haugen, Technology and Human Rights: Friends or Foes? Highlighting Innovations Applying to Natural Resources and Medicine (Republic of Letters 2012); Aurora Plomer, 'The Human Rights Paradox: Intellectual Property Rights and Rights of Access to Science' (2013) 35 Human Rights Quarterly 143; Aurora Plomer, Patents, Human Rights and Access to Science (Edward Elgar 2015); Helle Porsdam and Matthias Mann, 'The Right to Enjoy the Benefits of Scientific Progress and Its Applications - Report 2012 (A/HRC/20/26)' in Lucky Belder and Helle Porsdam (eds), Negotiating Cultural Rights: Issues at Stake, Challenges and Recommendations (Edward Elgar 2017) 79; William A Schabas, 'Study of the Right to Enjoy the Benefits of Scientific and Technological Progress and Its Applications' in Yvonne Donders and Vladimir Volodin (eds), Human Rights in Education, Science and Culture: Legal Developments and Challenges (UNESCO/Ashgate 2007) 273; Lea Shaver, 'The Right to Science and Culture' (2010) 2010 Wisconsin Law Review 121; Lea Shaver, 'Intellectual Property and the Right to Science and Culture: The Reports of the Special Rapporteur in the Field of Cultural Rights' in Christophe Geiger (ed), Intellectual Property and Access to Science and Culture: Convergence or Conflict?, Global Perspectives for the Intellectual Property System, CEIPI-ICTSD, Issue No 3, December 2016, 30; Cristian Timmermann, 'Sharing in or Benefiting from Scientific Advancement?' (2014) 20 Science and Engineering Ethics 111; Jeffrey H Toney and others, 'Science and Human Rights: A Bridge towards Benefiting Humanity' (2010) 32 Human Rights Quarterly 1008.

${ }^{8}$ The Committee's General Comments are authoritative interpretations of the ICESCR and its provisions. Even if not legally binding, they do have considerable legal weight. As 'any subsequent practice in the application of the treaty which establishes the agreement of the parties regarding its interpretation', they could be seen to be related to 'the context' of the Covenant for purposes of its interpretation: see Vienna Convention on the Law of Treaties (1969) (VCLT) (entered into force 27 January 1980) 1155 UNTS 331, art 31(3)(b).

${ }^{9}$ Edwin G Conklin, 'Science and Ethics', Address of the Retiring President of the American Association for the Advancement of Science, Indianapolis, 27 December 1937 (1937) 86(2244) Science 595, 601.

${ }^{10} \mathrm{See}$, for example, Stefan Collini, Speaking of Universities (Verso 2017) Ch 2.2 ('dirigiste forms of university administration'); Marc A Edwards and Siddhartha Roy, 'Academic Research in the 21st Century: Maintaining Scientific Integrity in a Climate of Perverse Incentives and Hypercompetition' (2017) 34 Environmental Engineering Science 51, 51 (a system of 'perverse incentives' and 'hypercompetition' corrupting science); Frank Furedi, 'Introduction to the Marketisation of Higher Education and the Student as Consumer' in Mike Molesworth, Richard Scullion and Elizabeth Nixon (eds), The Marketisation of Higher Education and the Student as Consumer (Routledge 2011) 1, 2 ('an increase in state intervention and the micro-management of university life'); Henry A Giroux, Neoliberalism 's War on Higher Education (Haymarket Books 2014) 'Introduction' (control amounting to a 'militarization of research'); Peter A Lawrence, 'The Mismeasurement of Science' (2007) 17 Current Biology R583, R585 ('increasingly complex grant applications and baroque research assessment exercises ... at the expense of research effort'); Grahame Lock and Chris Lorenz, 'Revisiting the University Front' (2007) 26 Studies in Philosophy and Education 405, 405 ('the ... hyper-bureaucratization [of research], via the 
and academic freedom, we shall most certainly witness the wholesale collapse and disintegration of modern science - or, as other observers describe it, 'the breakdown of scientific thought' ${ }^{11}$ - in the years to come. The state does have a role to play in science. It should encourage the flourishing of science. Beyond that, however, notably with regard to science in universities, clear limits on its role as an organiser of science need to be recognised. These restrictions concern primarily the a priori processes, activities and decisions in the science sector directed at 'producing' science. The a posteriori role of the state of facilitating access to the achievements of science by stimulating knowledge and innovation transfer is less contested, as long as state measures in this respect are in conformity with human rights (overprotection in patent law, for example, is problematic).

In what follows, four caveats will be addressed to all those tasked with clarifying the normative content of the REBSPA in Article 15(1)(b). Section 2 (Caveat 1) briefly introduces Article 15(1)(b) and (3) (the latter protecting 'the freedom indispensable for scientific research') and warns of confusing concepts such as the REBSPA, freedom of science, academic freedom, freedom of expression, and the right to education, in the UN Human Rights Covenants (that is, the International Covenant on Civil and Political Rights (ICCPR) ${ }^{12}$ and the ICESCR, both of 1966). Section 3 (Caveat 2) warns of overemphasising positive state duties under the REBSPA at the expense of negative state duties under that right and expresses doubt as to 'the manageability' of science. It proposes that an 'adequate' framework for science should entail limited state intervention and empowerment of the scientific fraternity. Section 4 (Caveat 3) warns of applying a corporate mindset towards science in universities and research institutions. Section 5 (Caveat 4) briefly introduces, to then warn of shortcomings in, the recently updated Recommendation on Science and Scientific Researchers of the United Nations Educational, Scientific and Cultural Organization (UNESCO) of 2017. ${ }^{13}$ The Recommendation is not a perfect blueprint for giving content to the REBSPA.

The intention of the article is not to say conclusively how things should be but, in many ways, to say how they should not be, or at least to raise questions. Definite answers to many of the issues require further in-depth thinking. Yet, the article will outline broad principles for a science system as this should be held to be envisaged by the REBSPA by relying on the concept of 'adequacy for science'. Throughout relying on this test, the article concludes with a set of 22 recommendations summarising how the REBSPA should be construed so as to duly respect

imposition of so-called evaluation, assessment and accreditation schemes, the latest avatars of the managerialist ideology').

${ }^{11}$ See Ylva Hasselberg, Sharon Rider and Alexandra Waluszewski, 'Introduction' and 'Conclusion: On the Verge of Breakdown' in Sharon Rider, Ylva Hasselberg and Alexandra Waluszewski (eds), Transformations in Research, Higher Education and the Academic Market: The Breakdown of Scientific Thought (Springer 2013) Chs 1 and 14.

${ }^{12}$ International Covenant on Civil and Political Rights (1966) (entered into force 23 March 1976) 999 UNTS 171 (ICCPR).

${ }^{13}$ UNESCO General Conference, Recommendation on Science and Scientific Researchers, UNESCO Doc 39 C/Res 85, 13 November 2017. 
scientific and academic freedom (Section 6). Future research would have to concretise the exact implications of the suggestions made.

The discussion occasionally refers to German law. This must be understood in the context of the fact that freedom of science is historically a 'German' idea. ${ }^{14}$ Freedom of science has its roots in the philosophy of Wilhelm von Humboldt (1767-1835), the Frankfurt Constitution of 1849, and the German concept of 'Wissenschaftsfreiheit' (freedom of science). This notion subsequently influenced legal developments in other Continental European countries and also the United States. Today, German case law probably constitutes the richest interpretative source of the concept of freedom of science.

Freedom of science, scientific freedom, and freedom of (scientific) research are used as synonyms in this article. 'Science', in this article and as internationally understood, refers to the organised attempt of individuals or groups to objectively study any field of knowledge, including the humanities and social sciences (economics, education, history, law, linguistics, philosophy, politics, psychology, and so on), in which theoretical elements are capable of being validated. ${ }^{15}$

\section{The Need for Conceptual Clarity: The REBSPA, Freedom of Science, Academic Freedom, Freedom of Expression, and the Right TO EDUCATION}

Caveat 1 (Conceptual Clarity): One should not confuse conceptual issues. Doctrinal clarity should prevail on how the REBSPA, freedom of science, academic freedom, freedom of expression and the right to education in the UN Human Rights Covenants interrelate. This is necessary in order to adequately ascertain and delimit the entitlements of different right-holders under the various rights and to set appropriate limits for state regulation under the REBSPA.

As an overview of this section, Article 15(1)(b) of the ICESCR protects every person's right to benefit from science. This right has three accepted pillars: freedom of science, enjoyment of the benefits of scientific progress, and protection from adverse effects of science. Regarding the first pillar, freedom of science, this entitles right-holders to claim that the freedom of another person, the scientist, be respected. Scientists, however, enjoy freedom of science as their own right, too: implicitly under Article 15(1)(b) and expressly under Article 15(3) (this referring to freedom of scientific research). Academic freedom is a special, 'enhanced' form of freedom of science, applicable to academics in higher education institutions only. The UN Human Rights Covenants, while thus expressly referring to scientific freedom, do not expressly mention academic freedom. Yet, Article 15 provides a common basis for recognising the rights of all scientists, within and beyond the higher education sector. However, academic freedom, entailing as it does clearly nuanced and more robust rights than 'ordinary' freedom of science, is probably

\footnotetext{
${ }^{14}$ See Christian Starck, 'Freedom of Scientific Research and Its Restrictions in German Constitutional Law' (2006) 39 Israel Law Review 110, 110-11 ('a German creation ... reproduced ... in many ... European state constitutions').

${ }^{15}$ See, notably, UNESCO Recommendation 2017 (n 13) para 1(a) (definition of 'science', 'sciences').
} 
better dealt with under Article 13 of the ICESCR on the right to education. Both scientific and academic freedom differ significantly from freedom of expression. In various ways, the state's active regulation under the REBSPA, intended to benefit citizens, may readily impact on scientific and academic freedom as a precondition for scientific progress, and thus, ironically, actually impede science benefiting society. Finally, the right to science, the REBSPA, attains human rights quality only if its focus is on disinterested, that is, purpose-free science, as accompanied by freedom of enquiry.

\subsection{The REBSPA and Freedom of Science in Article 15 of the ICESCR: Freedom of Science - An Element of the REBSPA, but also a Separate Right}

Commentators and experts agree that the REBSPA in Article 15(1)(b) of the ICESCR comprises three elements:

- freedom of science;

- enjoyment of the benefits of scientific progress; and

- protection from adverse effects of science. ${ }^{16}$

Hence, as much as the REBSPA is participation in the benefits of science and protection of human dignity against the harmful consequences of science, it is also freedom of science. The crucial rationale for the protection of freedom of science must be seen to lie in the fact that it makes possible the discovery of the truth. ${ }^{17}$ Scientific truth may, in turn, yield beneficial applications of science. While the second and third elements of the REBSPA, as mentioned here, rather signify positive state regulation, freedom of science rather signifies negative state abstention. There is an inherent tension between the former two and the latter element, a tension that requires a delicate balancing of the respective positive and negative state duties implicated.

The question, of course, is according to which criterion this balancing should take place. As already indicated, this article proposes the concept of 'adequacy for science' in this regard. The term signifies that structures, arrangements and decisions in the field of science must be such as will be 'in the best interest of science and scholarship' - rather than, for example, that of political, economic or social usefulness or expedience. The term connotes respect for the intrinsic requirements of science. It connotes the according of a central role to scientists themselves in organising science, appreciating that they, by reason of their training and experience, understand the needs of science "best' ${ }^{18}$ Another question relates to who should do the balancing. As will be explained

\footnotetext{
${ }^{16}$ See Saul, Kinley and Mowbray (n 6) 1215 (identifying these three aspects of the right in art 15(1)(b)). See also UNESCO, The Right to Enjoy the Benefits of Scientific Progress and Its Applications (Venice Statement), 2009, 13-20, para 13 (recognising, more or less, these three aspects of the right in art 15(1)(b) in para 13(a), (b) and (c), respectively).

${ }^{17}$ See the sources cited at $\mathrm{n} 43$ in this regard.

${ }^{18}$ The term 'adequacy for science' as used in this article is modelled on the German law concept of 'Wissenschaftsadäquanz', which has a related meaning, often used as a yardstick when assessing whether governance arrangements in institutions of science are constitutional in the sense that they ensure that decisions on science that are collective in nature will be 'adequate for science': see, for example, BVerfG (Federal Constitutional
} 
further on, the essential contours of the balance are to be drawn by framework legislation, with the courts constitutionally safeguarding that this is 'adequate for science' - and, therefore, is in conformity with human rights. ${ }^{19}$

Article 15 of the ICESCR protects 'cultural rights'. Whereas Article 15(1)(b) lays down the REBSPA, Article 15(1)(a) protects the right '[t]o take part in cultural life' and Article 15(1)(c) guarantees the right of creators ' $[\mathrm{t}] \mathrm{o}$ benefit from the protection of the moral and material interests resulting from [their] scientific, literary or artistic production[s]'. In terms of Article 15(2), states parties must take the steps 'necessary for the conservation, the development and the diffusion of science and culture'. Article 15(4) enjoins them to 'recognise the benefits to be derived from the encouragement and development of international contacts and co-operation in the scientific and cultural fields'. Note should be taken of Article 15(3), which requires states parties to 'undertake to respect the freedom indispensable for scientific research and creative activity'. The latter provision thus provides an additional basis for freedom of science (here, as the immediate right of scientists). In many ways, Article 15(3) constitutes a counterpoise to the positive elements of Article 15(1)(b), to Article 15(1)(c), and to Article 15(2) and (4), offering protection against threats of excessive or inappropriate state action sought to be justified under these provisions.

The Venice Statement on the Right to Enjoy the Benefits of Scientific Progress and its Applications - adopted following experts' meetings initiated by UNESCO in 2007, 2008 and $2009^{20}$ - elaborates on the normative content of the REBSPA, identifying its stated three elements. In terms of the Venice Statement, the REBSPA accordingly requires, firstly, the creation of an enabling environment for the conservation, development and diffusion of science, notably including freedom of science, ${ }^{21}$ secondly, enjoyment of the benefits of scientific progress (on a non-discriminatory basis), ${ }^{22}$ and, thirdly, protection from the abuse and adverse effects of scientific progress. ${ }^{23}$

The Venice Statement refers to negative duties of restraint in the field of science in a number of instances. It states that 'freedom of inquiry is a vital element in the development of science in its broadest sense'. ${ }^{24}$ Further, the right in Article 15(1)(b) 'is inextricably linked' to the freedom indispensable for scientific research as enshrined in Article 15(3). ${ }^{25}$ The enabling environment for science to be created 'implies inter alia academic and scientific freedom'. ${ }^{26}$ It may consequently be noted that the Venice Statement views Article 15(1)(b) and (3) as also providing a basis for academic freedom, a freedom that will be separately defined and commented on under the next

Court, Germany), BVerfGE 127, 87 - Hamburgisches Hochschulgesetz [Hamburg University Law], 20 July 2010 , para 91 (the court in this case emphasising that the participation of scientists in the organisation of science is to offer protection against decisions that are 'inadequate for science' ('wissenschaftsinadäquat')).

${ }^{19}$ See subs 3.3 below.

${ }^{20}$ UNESCO, Venice Statement (n 16).

${ }^{21}$ ibid para 13(a).

22 ibid para 13(b).

23 ibid para $13(\mathrm{c})$.

24 ibid para 8.

25 ibid para $12(\mathrm{~d})$.

${ }^{26}$ ibid para 13(a). 
two headings. ${ }^{27}$ An indication of the potential normative content of freedom of science (with academic freedom being a concretised form thereof) is also provided by the UNESCO Recommendation on Science and Scientific Researchers of 2017. ${ }^{28}$

State obligations to respect the REBSPA include the duty 'to respect the freedoms indispensable for scientific research'. ${ }^{29}$ The obligation to respect, firstly, not only gives rise to a claim accruing to the person entitled to benefit from science but, secondly, it also confirms a separate right of scientists, reinforcing that under Article 15(3). Regarding the former, individuals may thus claim that scientists' freedom of enquiry be respected. This gives the latter, the scientist's own right, a strong sense of duty. Scientists must exercise their freedom primarily in the interest of society at large, ${ }^{30}$ which benefits from science only where it is free and can lead to a discovery of the truth. ${ }^{31}$ To better explain this, society bestows a duty especially on university scientists to explore, and, moreover, to do so sincerely. In return, it accords substantial freedom to scientists so that they are, in fact, able to explore and discover. Only that freedom makes possible discovery of 'maximum' truth - as pointed out above, the crucial rationale for the protection of freedom of science. The UNESCO Recommendation of 2017 thus broadly states that scientific researchers have the 'responsibilit[y] ... to pursue, expound and defend the scientific truth as they see it' ${ }^{32}$ Once science is engaged to serve particular interests of state or industry and freedom is thus limited, science can, at best, furnish a compartmentalised version of the truth. This is so because, where science is planned in accordance with external goals, the natural operation of what the discussion below describes as the autonomous ('uncontrollable') laws of science is interfered with. ${ }^{33}$ Furthermore, science can never be as non-partisan and in the common (nonparticular or non-proprietary) interest as where it remains free from instrumental concerns. Hence, there is a special need for disinterested science, as that furthers 'maximum' truth. Disinterested science presupposes free science. The more disinterested science is to be, the freer it must be.

Apart from negative state obligations to respect (that is, to not interfere with) the right, the REBSPA in Article 15(1)(b) entails positive state obligations to protect the right by preventing infringement by third parties (of significance specifically where research is undertaken by private

\footnotetext{
${ }^{27}$ See subss 2.2 and 2.3 below.

${ }^{28}$ In this regard, the reader is referred to subs 5.1 below, which summarises the scientific and academic freedom rights protected by UNESCO Recommendation 2017 (n 13).

${ }^{29}$ UNESCO, Venice Statement (n 16) para 14(a).

${ }^{30}$ It should be noted that the 'sense of duty' does not imply that scientists should work 'for the economy'. As the further discussion will demonstrate (see, eg, subss 2.5, 3.1 (first four paragraphs), 4.1 or 5.3 below), this duty is owed to society at large. It is about elevating humanity, not about producing 'useful' insights.

${ }^{31}$ For this reason, freedom of science is described in German constitutional theory as a fundamental right 'in favour of' third parties ('drittnütziges Grundrecht'). The term originates with Hartmut Schiedermair, 'Die deutsche Universitätsreform im Jahre 1983' in Wolfgang Zeidler, Theodor Maunz and Gerd Roellecke (eds), Festschrift Hans-Joachim Faller (CH Beck 1984) 217, 219 ff (in German). See also Bernhard Kempen, 'Kapitel I: Grundfragen des institutionellen Hochschulrechts' in Michael Hartmer and Hubert Detmer (eds), Hochschulrecht: Ein Handbuch für die Praxis (2nd edn, CF Müller 2011) 1 para 15 (in German).

${ }^{32}$ UNESCO Recommendation 2017 (n 13) para 16(a)(i).

${ }^{33}$ See subs 3.1 below.
} 
industry $)^{34}$ and positive state obligations to fulfil (that is, realise) the right - triggered, in particular, by Article 15(2) and (4) as read with Article 2(1). ${ }^{35}$ Audrey Chapman holds that obligations to fulfil could cover, inter alia:

- an explicit government commitment to the development of science and technology;

- setting policies and establishing institutions to promote the development and diffusion of science;

- setting priorities for and channelling sufficient investment into the development of science and technology; and

- developing laws, institutions and policies to monitor and regulate science and technology. ${ }^{36}$

As a human right, the REBSPA would oblige states parties to observe certain principles. They would have to 'evaluate the implications of developing and making available areas of science and technology on human dignity'. ${ }^{37}$ They would have to ensure that 'the freedom and opportunity to benefit from scientific and technical advancement be broadly diffused within a nation "without discrimination of any kind". ${ }^{38}$ They would further have to make "specific investments in science and technologies likely to benefit those at the bottom of the economical and social scale'. ${ }^{39}$ They would also have to implement 'a right to societal decision making on setting priorities for and major decisions regarding the development of science and technology' ${ }^{40}$

\subsection{Academic Freedom as a Special or 'Enhanced’ Version of Freedom of Science}

As will be explained under this heading, it is important to distinguish between academic freedom and 'ordinary' freedom of science, as the nature or degree of protection to be accorded to either will have to differ.

Academic freedom is sometimes used as an umbrella concept for values and rights - some of them of human rights pedigree - that should prevail in education, either generally or at specific levels of the education system. ${ }^{41}$ At other times, it is used as an umbrella concept for human rights that should prevail at all or certain levels of the education system. These human rights

\footnotetext{
${ }^{34}$ The private sector is financing around 60 per cent of research and development in industrialised countries: Audrey R Chapman, 'Towards an Understanding of the Right to Enjoy the Benefits of Scientific Progress and Its Applications' (2009) 8 Journal of Human Rights 1, 24.

${ }^{35}$ For an elucidation of obligations to respect, protect and fulfil in relation to art 15(1)(b), see ibid 18-27.

36 ibid 24-25 (mentioning these and various other functions of obligations to fulfil).

37 ibid 11.

38 ibid 13.

39 ibid 14.

40 ibid 15.

${ }^{41}$ Hence, it has been stated that integrity, creativity, responsibility and confidence are the most important values in higher education: presentation by Professor Caroline Parker, Manager and Co-ordinator of Glasgow Caledonian University's Values Project, 'Values in Practice: Building Engagement and Changing Culture in Higher Education', 10 May 2017, Magna Charta Observatory, Rectorate, University of Bologna, Bologna (Italy). Elsewhere, it has been stated that the prime values in higher education are freedom, trust, education and community: The Manifesto: Reclaiming Our University (2016) para 7, https://reclaimingouruniversity.wordpress.com.
} 
include, for example, freedom of expression in schools or on campus, the right to express personality, rights of non-discrimination, freedom of assembly or association, freedom of religion, freedom of teaching or research, and similar. ${ }^{42}$ In the context of human rights law proper, however, academic freedom should only be given a strict meaning, namely that related to its key function. As in the case of freedom of science, discovery of the truth constitutes this key function, the crucial rationale for the protection of academic freedom. ${ }^{43}$ Not according academic freedom its strict meaning (set out below) would water down the effectiveness of academic freedom as a guarantor of the discovery of the truth and the advancement of knowledge for the benefit of society at large.

Academic freedom in a strict sense is the human right as it has been defined in paragraph 27 of the UNESCO Recommendation concerning the Status of Higher-Education Teaching Personnel of $1997 .{ }^{44}$ It is:

the right ... of higher-education teaching personnel ..., without constriction by prescribed doctrine, to freedom of teaching and discussion, freedom in carrying out research and disseminating and publishing the results thereof, freedom to express freely their opinion about the institution or system in which they work, freedom from institutional censorship and freedom to participate in professional or representative academic bodies. ${ }^{45}$

To buttress this right, it needs to be accompanied by institutional autonomy, self-governance, collegiality and tenure. ${ }^{46}$ Institutional (or university) autonomy 'is the institutional form of academic freedom'. ${ }^{47}$ It offers protection against intrusion by the state (or anybody else) in the affairs of the university. Self-governance refers to the right of academics to take part in the governing bodies of, and to elect a majority of representatives to academic bodies within a higher education institution. ${ }^{48}$ Collegiality means shared responsibility, participation of all concerned in internal

\footnotetext{
${ }^{42}$ Like a former UN Special Rapporteur on the Right to Education, this author refers to these as 'rights in education' rather than 'academic freedom': Klaus D Beiter, The Protection of the Right to Education by International Law: Including a Systematic Analysis of Article 13 of the International Covenant on Economic, Social and Cultural Rights (Martinus Nijhoff 2006) 476-78, 492-506, and the references there to the reports of the first UN Special Rapporteur on the Right to Education, Katarina Tomaševski. Academic freedom stricto sensu should be seen as one of the several human rights covered by academic freedom in this wide sense.

${ }^{43}$ See, for example, Ronald Dworkin, 'We Need a New Interpretation of Academic Freedom' in Louis Menand (ed), The Future of Academic Freedom (University of Chicago Press 1996) 181, 185-89 (identifying discovery of the truth and the promotion of ethical individualism as the rationales); Eric Barendt, Academic Freedom and the Law (Hart 2010) 53-63 (discovery and non-suppression of the truth and intellectual independence as rationales); Beiter, Karran and Appiagyei-Atua (n 7) 128-32 (discovery and non-suppression of the truth and ethical individualism, both as functions of human dignity, as rationales). See also text to $\mathrm{n} 17$.

${ }^{44}$ UNESCO General Conference, Recommendation concerning the Status of Higher-Education Teaching Personnel, UNESCO Doc 29 C/Res 11 (1997).

${ }^{45}$ ibid para 27 (emphasis added). 'Higher-education teaching personnel' means not only teachers, but also researchers in higher education: ibid para 1(f).

${ }^{46}$ See the following provisions of the Recommendation dealing with these aspects: ibid paras 17-21 (institutional autonomy), paras 31-32 (self-governance and collegiality), paras 45-46 (security of employment, including tenure).

${ }^{47}$ ibid para 18.

48 ibid para 31 .
} 
decision making, and consultative mechanisms in respect of academic and various administrative matters at all levels within a higher education institution. ${ }^{49}$ Tenure entails permanent employment contracts for academic staff, not easily terminable on operational grounds (and obviously not terminable for exercising one's academic freedom). ${ }^{50}$ The UNESCO Recommendation of 1997 makes it clear that individual academic freedom, self-governance and collegiality are essential components of institutional autonomy. ${ }^{51}$ Hence, where many universities nowadays construe autonomy as the power to improve ranking, to promote reputation and to enhance earnings, this amounts to a perversion of the original meaning of the term. In many ways, autonomy is an entitlement deduced from and should thus serve academic freedom. Autonomy must serve the inherent requirements of science. It must serve safeguarding a science system 'adequate for science'.

As indicated, in the context of human rights law proper, academic freedom should only have its strict meaning. When the Committee on Economic, Social and Cultural Rights, in its General Comment No 13 on the Right to Education, thus states that 'staff and students throughout the education sector are entitled to academic freedom', ${ }^{52}$ this statement is, with all due respect, not correct. As Malcolm Tight emphasises, 'academic freedom only applies to academics engaged in teaching, scholarship, etc., and not to other groups ... e.g. secondary school teachers'. ${ }^{53}$ What the Committee perhaps meant to say is that 'rights in education' are to be enjoyed throughout the education sector. ${ }^{54}$ The role of primary and secondary schools is not to conduct a scholarly search for the truth. They do not need comparable autonomy from the state. Self-governance and collegiality as safeguards to ensure decisions on science that are collective in nature will be 'adequate for science' - because the academy better understands the inner workings of science than administrators - play no role whatsoever. ${ }^{55}$ The state has extensive powers of regulation with regard to primary and secondary schools.

Academic freedom may be stated to be a special form of freedom of science, the latter expressly provided for in Article 15(3) ('freedom indispensable for scientific research') and implicitly in Article 15(1)(b) of the ICESCR. ${ }^{56}$ While freedom of science relates to scientific endeavour in a more general or inclusive way, applying within and beyond universities, academic freedom is applicable solely in the higher education (university) context. ${ }^{57}$ As the term 'academic freedom' already indicates, this freedom applies to academics only. Academics are members of a

\footnotetext{
49 ibid para 32.

${ }^{50}$ See Beiter, Karran and Appiagyei-Atua (n 7) 138-40 (roughly describing tenure in this way).

${ }^{51}$ UNESCO Recommendation 1997 (n 44) paras 17, 20, 21.

${ }^{52}$ UN Committee on Economic, Social and Cultural Rights, General Comment No 13: The Right to Education (Art. 13 of the ICESCR) (8 December 1999), UN Doc E/C.12/1999/10, para 38.

${ }^{53}$ Malcolm Tight, 'So What Is Academic Freedom?' in Malcolm Tight (ed), Academic Freedom and Responsibility (Society for Research into Higher Education and Open University Press 1988) 114, 120.

${ }^{54} \mathrm{On}$ 'rights in education', see n 42 and accompanying text.

${ }^{55}$ On the term 'adequacy for science', see n 18 and accompanying text.

${ }^{56}$ Freedom of science is also termed 'intellectual freedom', 'scientific freedom', or 'Wissenschaftsfreiheit': see Barendt (n 43) 38.

${ }^{57}$ Very clear in this sense: see ibid 38, 54-55 (explaining that academic freedom is a special case of the more general freedom of science, the former applicable in universities and comparable institutions only).
} 
university who teach or do research. ${ }^{58}$ 'Scientific' or 'academic' thus has nothing to do with the field of study concerned, or with the approach adopted (that is, whether a rational, 'scientific' approach, or a more scholarly, 'academic' approach). It relates only to the question: are we dealing with science (and this includes the humanities and social sciences) within or beyond the university? In the former case, we are dealing with academic freedom (as a concretised freedom of science); in the latter case, with 'ordinary' freedom of science. 'University' here does not solely denote 'traditional' universities, but all higher education institutions broadly dedicated to the triad of learning, teaching and research as facilitating notably disinterested science. ${ }^{59}$

It is important to distinguish between academic freedom and freedom of science because academic freedom requires a much more robust form of protection than 'ordinary' freedom of science. In view of the special responsibility of those working in higher education institutions to discover the truth and to advance knowledge, and their consequent vulnerability to hostility, they need and are entitled to enhanced forms of protection. ${ }^{60}$ Eric Barendt underlines that, insofar as the justification for academic freedom is based on 'the special role of universities as places for the free exchange of ideas', it does not apply with the same force to those working in non-university research institutes or private companies conducting research. ${ }^{61}$ Although non-university research institutes, whether governmental or non-governmental (NGOs) - as the term is used here - serve the public interest (are not for-profit), they generally pursue more narrowly defined research objectives, even if they may also undertake a measure of pure science. Private companies are driven by mercantile interests. It is for this reason that academic freedom must be accorded an 'elevated' status when compared with the freedom of science on which researchers in non-university research institutes, or on which private companies or their research staff, would rely. ${ }^{62}$

\footnotetext{
${ }^{58}$ See 'Academic', Definition, Collins English Dictionary, https://www.collinsdictionary.com/dictionary/english/ academic (last visited 23 September 2018). Academic freedom may also be claimed by students in higher education. In terms of Humboldtian ideas, academic freedom comprises, inter alia, Lernfreiheit (freedom of study), Lehrfreiheit (freedom of teaching), and Forschungsfreiheit (freedom of research): see, for example, Sylvia Paletschek, 'Die Erfindung der Humboldtschen Universität: Die Konstruktion der deutschen Universitätsidee in der ersten Hälfte des 20. Jahrhunderts' (2002) 10 Historische Anthropologie 183, 183-84 (in German). Students in higher education are the main beneficiaries of freedom of study. Moreover, to the extent that they engage in research, they also hold freedom of research. In this vein, see also Barendt (n 43) 37-38.

${ }^{59}$ See Beiter, Karran and Appiagyei-Atua (n 7) 184-85 (academic freedom applicable in higher education institutions in this sense). Academic freedom can, therefore, also apply in teaching-intensive higher education institutions (polytechnics, colleges, Fachhochschulen, grandes écoles) or universities focusing on applied research (technical universities, institutes of technology). See Tight (n 53) 121 (suggesting that, in certain ways, academic freedom may also apply in institutions such as 'polytechnics, colleges, [and] many present day universities'). How extensive academic freedom rights are will depend on the specific context - for example, the type of institution involved or the academic rank of the right-holder concerned: see Beiter, Karran and Appiagyei-Atua (n 7) 184; in the same vein, see also Tight (n 53) 121.

${ }^{60}$ See Beiter, Karran and Appiagyei-Atua (n 7) 171-74, 186 (stressing the need for enhanced forms of protection for academics vis-à-vis other scientists and justifying this on the basis of their special responsibility).

${ }^{61}$ Barendt (n 43) 37.

${ }^{62}$ On how 'academic freedom' applies to universities and 'freedom of science' also beyond these to non-university research institutes and private companies, see subs 3.2 below.
} 
Accordingly, while the authorities of a non-university research institute or private company may lay down the research agenda and assign research roles, such restrictions do not apply in universities. ${ }^{63}$ Similarly, tenure only serves to buttress academic freedom in universities. It should also be noted that academic freedom functions as a principle for allocating responsibilities in universities and as an academic and university organising principle. ${ }^{64}$ The requirements of self-governance and collegiality, as laid down in the 1997 UNESCO Recommendation, give particular expression to these principles. These concepts do not play a role in private companies. In non-university research institutes, they play a reduced role. ${ }^{65}$

The distinction between academic freedom and freedom of science is also drawn by the two separate UNESCO Recommendations addressing the rights and duties of 'higher education teaching personnel' and 'scientific researchers', respectively. ${ }^{66}$ The Recommendation concerning the Status of Higher-Education Teaching Personnel of 1997, applicable to teachers and researchers in higher education, ${ }^{67}$ refers to Article 13(2)(c) of the ICESCR on the right to higher education ${ }^{68}$ and speaks of 'academic freedom' ${ }^{69}$ The Recommendation on Science and Scientific Researchers of 2017, applicable to scientific researchers 'irrespective of ... the legal status of their employer, or the type of organisation or establishment in which they work', ${ }^{70}$ alludes to Article 15 of the $\mathrm{ICESCR}^{71}$ and prefers the term 'intellectual freedom'. ${ }^{72}$

Any positive state regulation under the REBSPA which affects the negative freedom of enquiry will have to be scrutinised in a differentiated manner, depending on the precise context. Scrutiny of state action that affects academic freedom will, in accordance with what has just been stated, have to be much stricter than scrutiny of state action that affects freedom of science beyond universities. It is important, therefore, to always keep in mind that enhanced protection under academic freedom can only be claimed by teachers, researchers and students in universities, public or private, and by those scientists working in research bodies clearly linked to universities. $^{73}$ Consequently, academic freedom does not apply to scientists in non-university research institutes of government. It does not apply to or in higher education institutions established purely to make a profit (as these are, in effect, private companies). It also does not apply to or in think tanks, policy institutes or related NGOs. Naturally, it does not apply to or in public or

\footnotetext{
${ }^{63}$ Barendt (n 43) 37.

${ }^{64}$ Paulus J Zoontjens, Vrijheid van wetenshap: Juridische beschouwingen over wetenschapsbeleid en hoger onderwijs (WEJ Tjeenk Willink 1993) 81-83 (in Dutch).

${ }^{65}$ This does not mean that they are irrelevant in this context - on the contrary: see subs 5.7 below in this regard.

${ }^{66}$ See Beiter, Karran and Appiagyei-Atua (n 7) 182-87 (elaborating on this aspect).

${ }^{67}$ UNESCO Recommendation 1997 (n 44) paras 1(f), 2.

${ }_{68}^{6}$ ibid Preamble.

${ }^{69}$ ibid notably para 27.

${ }^{70}$ UNESCO Recommendation 2017 (n 13) para 2(a)(i).

${ }^{71}$ ibid Preamble. This refers to art 27(1) of the Universal Declaration of Human Rights (UNGA Res 217A (III), UN Doc A/810 (1948) 71), which subsequently became art 15(1)(a) and (b) of the ICESCR.

${ }^{72}$ UNESCO Recommendation 2017 (n 13) para 16(a)(i).

${ }^{73}$ See Beiter, Karran and Appiagyei-Atua (n 7) 184-85.
} 
private business corporations. ${ }^{74}$ In all these instances - and provided science as defined is pursued $^{75}$ - 'ordinary' freedom of science applies. ${ }^{76}$

Even if conceptually understood as a negative freedom, both academic and scientific freedom themselves entail duties on the state to respect, protect and fulfil. As a human or fundamental right, academic and scientific freedom may be enforced directly against public universities (as quasi-organs of the state) and private universities (as institutions serving the public interest that is, when essentially not-for-profit institutions). Following the same rationale, scientific freedom may, likewise, be enforced directly against public (and potentially certain private) non-university research institutes. Although scientific freedom can ordinarily not be enforced directly against private companies, employment disputes between researchers and the private companies employing them will have to be dealt with in terms of labour law interpreted, where relevant, in the light of scientific freedom. ${ }^{77}$

\subsection{Academic Freedom as Part of the Right to Education in Article 13 of the ICESCR}

The UN Human Rights Covenants do not expressly mention academic freedom. The REBSPA in Article 15(1)(b), co-jointly with the provisions of Article 15(3) of the ICESCR, provides a basis for the freedom rights common to scientists within and beyond universities. Academic freedom, however, concretises many aspects of freedom of science in the higher education context, adds protection that is particular to that context, and generally infuses university values into freedom of enquiry. Although Article 15 properly serves as the basis for constructing a theory of academic freedom, this author and colleagues have argued that: ${ }^{78}$

in the absence of a specific reference in Article 15 to the very context in which academic freedom operates - the sphere of higher education - it may be meaningful ... to find an additional basis, a more natural 'home', for the right to academic freedom in the U.N. Human Rights Covenants.

We argued that Article 13 of the ICESCR on the right to education provides that natural 'home'.$^{79}$ Extensively supporting this view, we explained that the first sentence of Article 13(1), which

\footnotetext{
${ }^{74}$ See ibid 185 fn 267.

${ }^{75}$ See $\mathrm{n} 15$ and accompanying text.

${ }^{76}$ Freedom of science accrues to every person involved in scientific endeavour. It may thus be claimed by ordinary citizens as researchers, researchers working for NGOs, researchers employed by state corporations or public nonuniversity research institutes pursuing a set research agenda, private companies conducting research, researchers in private companies, scientific publishers, as well as teachers, researchers and students in universities: see Beiter, Karran and Appiagyei-Atua (n 7) 167-68.

${ }^{77}$ Academic and scientific freedom can also be enforced directly against non-department public bodies, such as independent research councils or organisations, and against state libraries and archives. Some rights can potentially also be enforced against NGOs as philanthropic funders of research. Academic and scientific freedom can be enforced directly against university and even commercial scientific publishers.

${ }^{78}$ Beiter, Karran and Appiagyei-Atua (n 7) 175 (emphasis added).

${ }^{79} \mathrm{ibid}$ 175-88 and the various references there. See also Balakrishnan Rajagopal, 'Defending Academic Freedom as a Human Right: An Internationalist Perspective' (2003) No 33 International Higher Education 3, 5 (stating that
} 
'recognise[s] the right of everyone to education', in terms of a purposive interpretation, should be understood as an open-ended fundamental norm in the sphere of education. ${ }^{80}$ As such, it functions as the normative basis for a comprehensive, rights-based education system, including at the higher education level, and also covering the rights of teaching and research staff. ${ }^{81}$ Higher education accordingly really means learning, teaching and research, in higher education. This is a persuasive argument if one considers that these are inseparable, mutually reinforcing processes, all directed towards achieving the 'greater' overarching goals of science - science, rather than 'instruction', being what universities are for. ${ }^{82}$

\subsection{Freedom of Science and Academic Freedom are Different from Freedom of EXPRESSION}

Both freedom of science and academic freedom need to be clearly distinguished from freedom of expression. ${ }^{83}$ The former two freedoms entail additional entitlements and more robust speech rights than freedom of expression. This heightened position must also buttress the status of freedom of enquiry as one of the pillars of the REBSPA vis-à-vis the latter's more positive aspects.

Whereas freedom of expression relates in many ways to speech rights (covering oral and written statements), freedom of science and academic freedom also relate to permissible conduct -

\footnotetext{
'[a] ... way to think about academic freedom is as a right to education that has individual and collective dimensions that can only be discharged through complex relationships between students, faculty, institutions, the government, and the society', and further that 'a human right to education injects an ethical dimension into academic freedom').

${ }^{80}$ Beiter, Karran and Appiagyei-Atua (n 7) 179-80 (in support of such an interpretation relying on Beiter (n 42) 460-62, and Pius Gebert, Das Recht auf Bildung nach Art. 13 des UNO-Paktes über wirtschaftliche, soziale und kulturelle Rechte und seine Auswirkungen auf das schweizerische Bildungswesen (Leo Fürer 1996) 286-88 (in German)).

${ }^{81}$ Beiter, Karran and Appiagyei-Atua (n 7) 180-82.

82 The Committee on Economic, Social and Cultural Rights, in its General Comment No 13, deems academic freedom to be encompassed by art 13: General Comment No 13 (n 52) paras 38, 59 ('[T]he Committee has formed the view that the right to education can only be enjoyed if accompanied by the academic freedom of staff and students. ... [V]iolations of article 13 include ... the denial of academic freedom of staff and students'). The first UN Special Rapporteur on the Right to Education had held that academic freedom forms a part of the 'acceptability' - alternatively, the 'availability' - criterion of the right to education: UN Economic and Social Council, Commission of Human Rights, Annual Report of the Special Rapporteur on the Right to Education, Katarina Tomaševski (7 January 2002), UN Doc E/CN.4/2002/60, 13 (regarding 'acceptability'); UN Economic and Social Council, Commission of Human Rights, Progress Report of the Special Rapporteur on the Right to Education, Katarina Tomaševski (1 February 2000), UN Doc E/CN.4/2000/6, paras 42-44 (regarding 'availability').

${ }^{83}$ For want of suitable (or fully fledged) normative provisions in the European Convention on Human Rights (ECHR) ((1950) (entered into force 3 September 1953) 213 UNTS 221) protecting rights to science or education, the European Court of Human Rights (ECtHR) has started reading aspects of academic freedom into the right of freedom of expression in art 10 of the ECHR: see, notably, ECtHR, Sorguç v Turkey, App no 17089/03, 23 June 2009, paras 21, 35; and ECtHR, Mustafa Erdoğan v Turkey, App nos 346/04 and 39779/04, 27 May 2014, para 40. In the latter case, however, three judges, in a separate opinion, recognise that 'academic freedom transcends the scope of Article 10 in certain areas': Erdoğan v Turkey, joint concurring opinion of Judges Sajó, Vučinić and Küris, para 3. For a discussion of the Court's approach, see Beiter, Karran and Appiagyei-Atua (n 7) 155-59. The UN Human Rights Covenants protect the right to freedom of expression in art 19 of the ICCPR (n 12).
} 
permissible conduct includes, for example, using the equipment or facilities of a research laboratory or university department, conducting scientific experiments, or organising a conference or research teams ${ }^{84}$ Freedom of expression further cannot really serve as a concept from which to deduce rules aimed at governing the internal relationships (academic staff, students, governing and academic bodies) within the university. Academic freedom centrally functions as such a concept. ${ }^{85}$

Moreover, scientific and academic freedom, on the one hand, and freedom of expression, on the other, are based on two very different rationales. The latter is essentially about upholding democracy, entitling every person, as it were, to say whatever they desire in the interest of a multiplicity of views being heard. It even covers the right 'to tell lies' ${ }^{86}$ Scientific and academic freedom are more pronouncedly about discovering the truth and advancing knowledge (even if this is also crucial, eventually, in building a democratic society) ${ }^{87}$ Hence, scientific and academic freedom envisage 'special' speech rights. There are duties of objectivity and rigour that need to be observed. There is no right 'to tell lies'. For this reason, scientific and academic speech are subject to quality controls, taking the form of, for example, peer review. ${ }^{88}$ In the context of ordinary speech protected by freedom of expression, such controls do not really exist, ${ }^{89}$ and would (or should) readily amount to impermissible censorship. However, it is also true that limitations by law to further certain public goals (such as national security) may be imposed more easily with regard to freedom of expression than scientific or academic freedom. This is a consequence of the crucial value attached to the discovery of the truth and the 'sophisticated' nature of scientific and academic speech. Scientific and academic freedom may be regulated rather than limited by law. ${ }^{90}$ This insight must be kept in mind in as far as positive state regulation under the REBSPA may have 'an impact' on the negative freedom of enquiry.

In sum, because of the stated crucial value of truth for the advancement of society and the risk of attack to which revealing that truth exposes scholars, scientific and academic freedom entail more robust speech rights than does freedom of expression. In the literature a useful distinction has been drawn between intra-mural and extra-mural academic speech and academics' off-topic speech. In

\footnotetext{
${ }^{84}$ See Barendt (n 43) 21 (academic freedom covering permissible conduct; examples of permissible conduct).

${ }^{85}$ See Zoontjens (n 64) 81-83 (academic freedom as organisational principle in universities).

${ }^{86}$ This is, for example, how the US Supreme Court decision in Susan B. Anthony List v Driehaus 573 US (2014) may be interpreted, potentially legitimising the right to make false statements in political campaigning.

${ }^{87}$ See Barendt (n 43) 18-19, 54-55, and also Erdoğan v Turkey (n 83) joint concurring opinion of Judges Sajó, Vučinić and Kūris, paras 5-6 (highlighting these differing rationales).

${ }^{88}$ Barendt (n 43) 20-21. Beyond quality requirements, however, and ' $[w]$ ithin the field of expertise, scientific freedom protects virtually every utterance': Michael Hartmer, 'Was darf ein Hochschullehrer äußern?' (2015) 22(11) Forschung \& Lehre 908 (in German).

${ }^{89}$ Barendt (n 43) 20-21.

${ }^{90}$ Beiter, Karran and Appiagyei-Atua (n 7) 161. Regulating a fundamental right means for a competent actor, such as the legislator, to concretise that right, notably by clarifying its (pre)existing limits, through a process of identifying limits flowing from the very purpose of that right, and by balancing it with other fundamental rights, interests and values, thus establishing 'practical concordance' between that right and the various other rights, interests and values. Limiting a fundamental right means imposing new limits. As this measure is more drastic, it requires 'constitutional' permission in terms of an explicit general or specific limitation clause and may occur only by means of a law that meets narrowly defined requirements. Consequently, it will be exceptionally difficult to justify any limitation of scientific or academic freedom under the general limitation clause of art 4 of the ICESCR.
} 
the case of intra and extra-mural speech, academics speak within their area of expertise to experts and non-experts, respectively. ${ }^{91}$ In the case of off-topic speech, they speak outside their area of expertise. ${ }^{92}$ Intra-mural speech enjoys a higher level of protection than extra-mural speech, which in turn enjoys a higher level of protection than off-topic speech - which, in fact, enjoys protection as ordinary speech under freedom of expression. ${ }^{93}$ The different levels of protection reflect 'the (presumed) quality of the opinion and its (potential) contribution to the general interest'. ${ }^{94}$

\subsection{When Will the REBSPA Attain the Quality of a Human Right?}

The REBSPA, the right to science, while it must cater for various forms of scientific endeavour, will attain human rights quality only by focusing on science in a Weberian or Mertonian sense. In a nutshell, science in a Weberian or Mertonian sense means disinterested, free science - that is, that form of science best suited to promoting the emergence of 'maximum' truth, thus benefiting the common rather than particular interests, ${ }^{95}$ and thus most immanently directed at realising human dignity, the foundational value of human rights law. Max Weber, in his powerfully eloquent description of science as a vocation of $1919,{ }^{96}$ states that science only unfolds its value for society if it provides insights 'adding to knowledge' 97 - that is, insights that explain the world. Science must, however, not be guided by notions of value or worth, ${ }^{98}$ or usefulness or purpose. ${ }^{99}$ These are considerations foreign to the normative order of science - and ' $[\mathrm{t}]$ he different normative orders of the world [here notably science and politics] insolvably clash with each other'. ${ }^{100}$

\footnotetext{
${ }^{91}$ Jogchum Vrielink, Paul Lemmens and Stephan Parmentier, 'Academic Freedom as a Fundamental Right', League of European Research Universities, Advice Paper No 6, December 2010, paras 50, 54 (intra-mural speech means " "pure academic speech", i.e. expert utterances within the university or academic context in pursuit of teaching and research excellence'; extra-mural speech means 'interventions by academics in their areas of expertise ...e.g. in the media or during debates with the general public').

${ }^{92}$ ibid para 57 ('[s]peech falling outside of an academic's field(s) of expertise'). It is the 'academic' element that distinguishes extra-mural from off-topic speech: see Erdoğan v Turkey (n 83) joint concurring opinion of Judges Sajó, Vučinić and Kūris, para 6. Speech has an 'academic' element if (i) the person making the speech is an academic; (ii) the comments fall within the sphere of that person's research; and (iii) that person's comments amount to conclusions based on his or her academic expertise: ibid para 8.

${ }^{93}$ Vrielink, Lemmens and Parmentier (n 91) paras 48-56. Obviously, an arguable but scholarly statement on the Holocaust made by a professor of history in class to his or her students (intra-mural speech) must be treated differently from the same statement made by that professor on the radio and addressed to the ordinary public (extramural speech), in turn to be treated differently from the lay opinion on the Holocaust expressed by, say, a professor of economics in a public market place (off-topic speech).

${ }^{94}$ ibid para 48. The scheme outlined may be further refined by making it applicable to scientists who are not academics (and thus entitled to freedom of science rather than academic freedom) in the following way. They will similarly enjoy protection for intra-mural, extra-mural and off-topic speech on an equivalent sliding scale of degrees of protection described above. However, based on the public interest rationale, their intra and extra-mural speech enjoy lower respective levels of protection than that of academics.

${ }^{95}$ See nn 30-33 and accompanying text.

${ }^{96}$ Max Weber, 'Wissenschaft als Beruf' in Gesammelte Aufsätze zur Wissenschaftslehre (JCB Mohr (Paul Siebeck) 1922) 524 (in German).

97 ibid 541 ('wissenswert').

98 ibid 541-44 ('Sinn').

99 ibid 550 ('Zweck').

100 ibid 545.
} 
Robert Merton, in his famous article on the normative structure of science of 1942, identified the following as the imperatives of academic science: communism (common ownership of science), universalism (science must be non-partisan), disinterestedness (science must be purpose-free), and organised scepticism - CUDOS. ${ }^{101}$ The scientific community to this day continues to regard these criteria as essentially valid. ${ }^{102}$ According to John Ziman, science in the Mertonian CUDOS sense constitutes 'real science'. ${ }^{103}$ New modes of knowledge production, as resembling industrial science, follow a different model: the PLACE pattern. Science here is proprietary (not communalist), local (not universal), authoritarian (not disinterested), commissioned (not original), and expert (rather than sceptical). ${ }^{104}$ In simplified terms, while CUDOS is committed to 'the whole truth', PLACE is committed to 'nothing, but the truth', though not necessarily 'the whole truth'. ${ }^{105}$ This is so because it has to obey the material interests of bodies outside science. ${ }^{106}$ Requirements these days that academic science must have 'impact' move it away from CUDOS towards PLACE science. To qualify as a human right, grounded in human dignity, the REBSPA would primarily have to embody the CUDOS vision in terms of which science serves society best if it remains free from considerations of political, economic or social usefulness. ${ }^{107}$ Only this vision allows for the emergence of comprehensive, untainted, 'commonly-owned' truth as a precondition for scientific progress that benefits all.

\section{The ReBSPa, Positive and Negative State Duties, 'The Manageability' of Science, and a Science System 'Adequate for Science'}

Caveat 2 ('Adequacy for Science'): One should not overemphasise the state's positive duties of regulation under Article 15(1)(b) of the ICESCR at the expense of its negative duties under that provision. Science is inherently 'unmanageable'. Legislation in the field of science is important. It must protect freedom of enquiry and should assign ultimate competence for regulation and decision making to the scientific fraternity itself. The state's power of regulation under the REBSPA, and, likewise, protection levels for freedom of enquiry, should be different for private companies conducting research, non-university research institutes, and universities. The overall science system must be 'adequate for science'.

\footnotetext{
${ }^{101}$ As republished in Robert K Merton, The Sociology of Science: Theoretical and Empirical Investigations (Norman W Storer (ed), University of Chicago Press 1973) 267, 270-78.

${ }^{102}$ See Melissa S Anderson and others, 'Extending the Mertonian Norms: Scientists' Subscription to Norms of Research' (2010) 81 Journal of Higher Education 366, 391 (finding that the Mertonian norms 'have endured for over 65 years as part of the communal property of science').

${ }^{103}$ John Ziman, Real Science: What It Is, and What It Means (Cambridge University Press 2003) 33 ('The particular virtue of the Mertonian norms is that they emphasize practices and principles ... that genuinely distinguish science from other institutions and callings'). Ziman interprets the ' $\mathrm{O}$ ' in CUDOS as 'originality': ibid 40-42. 104 ibid 78-79.

105 ibid 176.

106 ibid 177.

${ }^{107}$ See Hamburgisches Hochschulgesetz [Hamburg University Law] case (n 18) para 90 ('[S]cience free from considerations of social utility and political expedience serves state and society in the final analysis best').
} 


\subsection{Positive vs Negative State Duties: Respecting the Autonomous Character OF SCIENCE}

Audrey Chapman stresses that 'the process of doing scientific research and the development of applications from that science [must] be consistent with fundamental human rights principles' ${ }^{108}$ She further emphasises that, while science may serve 'other purposes, even noteworthy goals', the REBSPA mandates that 'science be seen as an instrument for human benefit'. ${ }^{109}$ While that sounds very plausible, it is not always easy to distinguish between science for human benefit and science as part of a grander state plan directed primarily at enhancing economic growth, which states will often hypocritically argue automatically promotes economic, social and cultural rights. Science must first of all be directed at revealing knowledge and truth, whether that is economically useful or not. Usefulness to the economy may, or may not, emerge subsequently. Human benefit also concerns civil, political, social and cultural progress. In today's neoliberal climate, however, 'human benefit' has become equated with economic growth as an end in itself.

In 1945, Michael Polanyi, one of the great theorists on intellectual enquiry of the previous century, described the idea of subordinating science to the planning of socio-economic progress part of 'a general attack on the status of intellectual and moral life'. ${ }^{110}$ His adversary, John Bernal, a political supporter of communism, however, believed that the ideal of pure science was 'a form of snobbery'. ${ }^{111}$ More than fifty years of 'science policy' leave no doubt that Bernal's idea that research should be undertaken for its foreseeable socio-economic benefit has been triumphant. ${ }^{12}$

In the 1980s, Bengt-Åke Lundvall and Christopher Freeman undertook their innovation system studies, directed at understanding communication processes between creators and users in the innovation process so as ultimately to find ways of ensuring that science would contribute to a socially embedded economy. ${ }^{113}$ Little did they - and other social scientists building on their work, all with sympathies for the political left - know that the Organisation for Economic Co-operation and Development, the European Commission and other international organisations would crudely rely on their theories to justify a business-friendly 'economistic' approach towards science. ${ }^{114}$

Meanwhile, premised on neoliberal notions of global economic competitiveness and public accountability, there is a firm belief among many policy makers that there should be a 'science of science policy', directed at steering the growth of science and, with it, that of the

${ }^{108}$ Chapman (n 34) 11.

109 ibid $10-11$.

${ }^{110}$ Michael Polanyi, 'The Planning of Science' (1945) 16 Political Quarterly 316, 327.

${ }^{111}$ John D Bernal, The Social Function of Science (reprint, George Routledge 1939) 96.

${ }^{112}$ Acknowledging this state of affairs with unease, see John Ziman, 'The Republic of Science: Its Political and Economic Theory' (2000) 38 Minerva 21, 22-23.

${ }^{113}$ Bengt-Åke Lundvall, Product Innovation and User-Producer Interaction (Aalborg Universitetsforlag 1985); Christopher Freeman, Technology, Policy, and Economic Performance: Lessons from Japan (Pinter 1987).

${ }^{114}$ For a revealing description of the events, see Magnus Eklund, 'Science Policy in a Socially Embedded Economy' in Rider, Hasselberg and Waluszewski (n 11) 111, 115-17. 
economy. ${ }^{115}$ However, one may legitimately ask: where the outcome of research can be foreseen, is this still research? Is it not 'logically nonsensical' to still speak of research in this context? ${ }^{116}$ Moreover, where the delivery of external goods to the wider society becomes the prime purpose of science, and where, towards that end, comprehensive machinery to plan and execute science is put in place, does this not amount to 'technocratic method ... driving out the sphere of the ethical', eliminating '[any] sense of the academic community as a practice founded on a[n] [unconstrained] conversation'? ${ }^{117}$

It should also be remembered that every instance of state regulation in the field of science readily impacts on scientific or academic freedom. Naturally, no freedom is unbridled. However, where the nature of a right - the REBSPA - is such that positive state regulation under that right may not only impact on that right's negative component (that is, scientific or academic freedom) but even tends to frustrate scientific progress in itself and the achievement of the REBSPA as a whole, such regulation requires careful 'reasonableness' justification. Perhaps it is also for this reason that Chapman considers that the scope of obligations to fulfil under the REBSPA is unclear and needs further discussion in the human rights community. ${ }^{118}$

The danger with regard to Article 15(1)(b) lies in not establishing a suitable balance between the role of the state in positively organising science and its negative duty of restraint. In an article of 2016, this author and colleagues were the first in international human rights law to point out this fundamental concern: ${ }^{119}$

[T] he academic literature so far has focused on the right to freedom of scientific research as an aspect of the right to enjoy the benefits of scientific progress and its applications, generally putting the stress on the positive obligations of states to regulate the sphere of science, according rather stepmotherly attention to negative obligations of restraint. Important as securing a wider participation of society in the enjoyment of the benefits of science is, excessive state regulation (and choice of the wrong regulatory instruments), failing to appreciate that science, in principle, is not susceptible to 'being managed', may well 'suffocate' freedom of scientific research.

The German Constitutional Court, in its seminal Hochschul-Urteil [University Judgment] of 1973, accordingly stresses 'the autonomous character of science', the fact that science follows its own laws, thus requiring large-scale state abstention from interference in the field of

\footnotetext{
${ }^{115}$ See John H Marburger III, 'Why Policy Implementation Needs a Science of Science Policy' in Kaye Husbands Fealing and others (eds), The Science of Science Policy: A Handbook (Stanford University Press 2011) 9, 13, 21 (lamenting 'perverse distributions of resources' for science, stressing the need to 'enhance U.S. economic competitiveness', and describing ' $[\mathrm{t}]$ he existence of an academic field of science of science policy [as] a necessary precondition'). John H Marburger III was Science Adviser to former US President George W Bush.

${ }^{116}$ In this sense, see also Ziman (n 112) 23.

${ }^{117}$ In this sense, see Ronald Barnett, 'The Idea of Academic Administration' (1993) 27 Journal of Philosophy of Education 179, 190 (relying on ideas of Jürgen Habermas and Alasdair MacIntyre) (emphasis in original).

${ }^{118}$ Chapman (n 34) 24.

${ }^{119}$ Beiter, Karran and Appiagyei-Atua (n 7) 166-67.
} 
science. ${ }^{120}$ Scientists themselves have emphasised that science cannot 'be managed'. Max Perutz, who received the Nobel Prize in Chemistry in 1962, expressed the view that creativity in science, as in the arts, could not be organised, but arose spontaneously from individual talent. While wellrun laboratories could foster it, hierarchical organisation, bureaucratic rules and futile paperwork could kill it. Discoveries could not be planned but, as he described it, they popped up in unexpected corners. ${ }^{121}$

The history of science reveals that many groundbreaking scientific discoveries are the result of scientists ignoring, subverting or openly contesting rules, policies and decisions of their employers on what should be researched and how. James Watson, one of the four co-discoverers of the structure of DNA, relates how he and his colleague Francis Crick, as young scientists, had been instructed to discontinue their study of DNA. Gladly they continued with it secretly, as this led to the discovery of the double helix structure of DNA. In 1962, Watson and his colleagues won the Nobel Prize in Physiology or Medicine for their discovery. ${ }^{122}$ The history of science also provides ample proof of detours, coincidences and surprises that were not susceptible to being achieved in a systematic and linear manner. ${ }^{123}$ Hence, many groundbreaking inventions - be they penicillin, polyethylene (plastic), Teflon, vulcanised rubber or X-rays - were, in this sense, made 'by mistake'. ${ }^{124}$ They did not flow from specific research plans with deadlines. ${ }^{125}$

At the basis of all creativity and innovation in science lies scientific or academic freedom, signifying the absence of unnecessary interferences with the wondrous but incomprehensible laws of scientific discovery. It has been observed that '[m]any academics are extremely

${ }^{120}$ BVerfG (Federal Constitutional Court, Germany), BVerfGE 35, 79 - Hochschul-Urteil [University Judgment], 29 May 1973, para 128. The case concerned the question whether legislation in the early 1970s violated scientific freedom. The legislation granted participatory rights in the self-governance of universities to academic staff other than full professors, students and non-academic staff. The Court held that it did not, provided professors retained a prominent or decisive influence with regard to questions of teaching and research, respectively. Of importance here are the Court's general observations on the limits of state regulation in the field of science in universities. The Court explained that, while the state had a duty to ensure the functionality of the university system as a whole (paras 132, 145), the scientist's freedom of scientific endeavour entailed a certain space of 'absolute freedom from any interference by the state. This space covers especially all those processes, behaviours and decisions in gaining, interpreting and communicating insights which are based on the autonomous character of science ('wissenschaftliche Eigengesetzlichkeit'). ... To ensure that research and teaching can orient themselves towards the pursuit of the truth without impediment ... science has been declared a sphere of personal and autonomous responsibility of the individual scientist free from state heteronomy' (para 128).

${ }^{121}$ Max F Perutz, I Wish I'd Made You Angry Earlier: Essays on Science, Scientists and Humanity (exp edn, Cold Spring Harbor Laboratory Press 2003) ix.

${ }^{122}$ For a description of the events, see James D Watson, The Double Helix: A Personal Account of the Discovery of the Structure of DNA (Simon \& Schuster 2011) Ch 14. See also the interesting recent book by Franz M Wuketits, Außenseiter in der Wissenschaft: Pioniere - Wegweiser - Reformer (Springer 2015) (in German) (in which the author reports on 35 famous scientists from past and present, who, 'opposing rules and conventions', contributed greatly to scientific progress).

${ }^{123}$ Georg Krücken, 'Lässt sich Wissenschaft managen?' (2008) 41 Wissenschaftsrecht 345, 350 (in German).

${ }^{124}$ For these and many other examples of coincidental inventions, see Royston M Roberts, Serendipity: Accidental Discoveries in Science (Wiley 1989).

${ }^{125}$ A word has even been made up to describe this phenomenon: 'serendipity' - referring to the 'making [of] discoveries, by accidents and sagacity, of things which [one] [was] not in quest of'. The word originated with Horace Walpole in 1754: Robert K Merton and Elinor Barber, The Travels and Adventures of Serendipity: A Study in Sociological Semantics and the Sociology of Science (Princeton University Press 2004) 1-2 (quoting Walpole). 
independent with a focus on intellectual creativity. They value a secure and stable environment where they can do their work alone'. ${ }^{126}$ John Hurley, in his study of 16 Nobel Physics laureates, found that they attached 'maximum possible importance ... to their own freedom of thought and behaviour, including their ability to choose their own work', and, by way of contrast, minimal importance to the supervision and evaluation of their research. ${ }^{127}$ Yet, states seem to have farreaching plans for what they wish the sciences to accomplish. This approach has been described as dangerous. Acclaimed German philosopher Julian Nida-Rümelin (and a former Minister of Culture in a Social Democrat government in Germany) points out that attempts to instrumentalise academia to achieve economic, technological, social or cultural advances rest on a fundamental fallacy, warning that historical experience shows that the instrumentalisation of academia for state, religious and economic purposes has always inhibited the innovative potential of science. ${ }^{128}$

This author fully appreciates the role of the state, of course, in the context of realising economic, social and cultural rights. Focusing for a moment specifically on the educational context, the author, in a monograph on the right to education in international law, has elucidated the comprehensive positive duties of the state when it comes to implementing a system of education at the primary and secondary levels, designing educational content, supervising educational attainment, and ensuring the absence of indoctrination. ${ }^{129}$ However, when it comes to higher education and science, the picture is more complex. Although the state needs to massively invest resources in the system of higher education and science, universities crucially depend on autonomy. One of the important purposes of autonomy is the protection of academic freedom. The main purpose of academic freedom, in turn, as explained, is to enable teachers and researchers, co-jointly with students, to advance 'the truth'. ${ }^{130}$ The truth - which, as Stefan Collini underlines, does not connote mere "usefulness"131 - benefits the progress of society. The academy should not be obstructed in its truth-finding mission. The reality, however, is that it is in the process of foregoing enjoyment of those rights that function as determinants of an environment promoting 'the best interest of science and scholarship' - an academic environment that may be described as 'adequate for science'. ${ }^{132}$ Genuine institutional autonomy, individual academic freedom, academic self-duty, ${ }^{133}$ self-governance, collegiality, and employment security and tenure are in

\footnotetext{
${ }^{126}$ Neil W Hamilton, 'Buttressing the Neglected Traditions of Academic Freedom' (1996) 22 William Mitchell Law Review 549, 558 (footnote omitted). The author, however, laments that academics also 'opt ... out of the practice world': ibid 559.

${ }^{127}$ John Hurley, Organisation and Scientific Discovery (Wiley 1997) 82.

${ }^{128}$ Julian Nida-Rümelin, Zur Krise beruflicher und akademischer Bildung (Bundeszentrale für politische Bildung 2014) 144-45 (in German).

${ }^{129}$ See Beiter (n 42).

${ }^{130}$ See subss 2.1, 2.2 and 2.4 above. For an analysis of the content of, and rationale for, institutional autonomy and academic freedom in the light of various scholarly and normative sources, see Beiter, Karran and Appiagyei-Atua (n 7) 123-25, 128-35, 181-82.

${ }^{131}$ Collini (n 10) Ch 11.1.

${ }^{132}$ On the term 'adequacy for science', see n 18 and accompanying text.

${ }^{133}$ Academics have manifold duties, nicely set out in Donald Kennedy, Academic Duty (Harvard University Press 1997). Apart from regulated forms of ensuring compliance with such duties, individual academics must also be recognised as having an important role themselves in construing, and self-sanctioning non-compliance with, these duties. The German Constitutional Court has stated that '[s]cience is a sphere of autonomous responsibility
} 
danger of becoming obsolete. ${ }^{134}$ Increasingly, the state and university 'managers' have come to decide on what should be taught and researched, and how. ${ }^{135}$ This is poison for the system of science. Based on their training, talent, scholarship and experience, scholars possess a 'scientific' or 'academic intuition', which tells them where knowledge lies. ${ }^{136}$ Presupposing their independence and enjoying rights of participation or self-regulation, they know best how to go about unearthing this. ${ }^{137}$ Over-regulation distorts or kills intuition.

\subsection{Different Rules for Private Companies, Non-University Research Institutes, and UNIVERSITIES}

Donald Braben notes that today's technology derives from scientific discoveries made decades ago, that managed creativity produces only what its managers specify, and that efficiency and accountability will often be the worst possible policies. ${ }^{138} \mathrm{He}$ accordingly proposes, somewhat exuberantly, that we should begin to create 'a twenty-first-century [Max] Planck Club', the members of which 'should hold themselves accountable only to Nature herself'. ${ }^{139}$ This may be somewhat overstating things, yet it conveys the message: scientific and academic freedom need to be taken more seriously. However, what then should the ambit, the delimitation, of the state's positive obligations under the REBSPA be to safeguard its negative freedom component so crucial to facilitating scientific progress? Which scheme of arrangements would be 'adequate for science'?

It may be useful to distinguish between private companies conducting research, nonuniversity research institutes, and universities. ${ }^{140}$ Non-university research institutes are specialist

principally free from external control': BVerfG (Federal Constitutional Court, Germany), BVerfGE 139, 148 Hochschulfusion [University Merger], 12 May 2015, para 68 (emphasis added).

${ }^{134}$ For detail on self-governance, collegiality and 'adequacy for science', see Beiter, Karran and Appiagyei-Atua (n 7) $125-27,135-38$.

${ }^{135}$ See Section 4 below, where this is commented on in the light of the existing literature. See also $\mathrm{n} 10$ and accompanying text.

${ }^{136}$ See, for example, Albert Einstein, 'Prologue' in Max Planck, Where Is Science Going? (WW Norton 1932) 10 ('There is only the way of intuition, which is helped by a feeling for the order lying behind the appearance and this Einfuehlung is developed by experience'); more recent, Peter J Bowler, 'Philosophy, Instinct, Intuition: What Motivates the Scientist in Search of a Theory?' (2000) 15 Biology and Philosophy 93, 100 (following an analysis of approaches adopted in science, the author concludes that 'rational argument often plays a surprisingly limited role in the decisions that shape the choice of world view or research strategy'. One has to do with 'personalitydriven factors corresponding to the "instinct"'). Hence, government and university bureaucrats ordinarily neither possess nor understand this instinct or intuition.

${ }^{137}$ John Hurley, in his book Organisation and Scientific Discovery, addresses the question of how most effectively to organise science in order to best facilitate creativity. He identifies the following as preconditions for 'scientific' or 'academic intuition', and thus scientific discovery: scientific knowledge and ability of researchers, their personality characteristics, adequate organisational resources, and appropriate organisational dynamics. The latter entail, inter alia, autonomy for scientists, a positive organisational culture, low hierarchies, trust, and reduced emphasis on evaluation: Hurley (n 127).

${ }^{138}$ Braben (n 1) 89.

139 ibid.

${ }^{140}$ Also Eric Barendt seems to approve of this categorisation for purposes of determining the ambit of rights: Barendt (n 43) 133-58. In the European Union, for example, roughly $45 \%$ of researchers work in the 'business enterprise sector', $12 \%$ in the 'government sector', $42 \%$ in the 'higher education sector', and $1 \%$ in the 'private 
research institutions, existing independently from universities, and pursuing research in a clearly defined field of science. They may be public (governmental) or private (non-governmental), but serve the public interest, evident notably in the fact that they are not pure for-profit institutions. Universities are all higher education institutions, public or private, broadly dedicated to the triad of learning, teaching and research as facilitating notably disinterested science. ${ }^{141}$ Pure for-profit non-university research institutes or universities rather qualify as companies. While 'academic freedom' applies only to universities, the more general 'freedom of science' also applies beyond these to non-university research institutes and private companies. ${ }^{142}$

With regard to private companies, the state should create incentives for research that promote (also) the public interest. Such incentives may exist by virtue of an adequate patent system. A patent establishes a time-limited monopoly awarded to the inventor, allowing him or her to exploit the technology developed. Current patent law, however, is marred by overprotection. This results in high prices for patented products and low productivity in the technology sector. ${ }^{143}$ Further innovation is stifled by bad patents being granted, for example, for inventions that do not meet genuine standards of non-obviousness or, especially in developing countries, the obligation to pay often excessive licensing fees in order to further develop patented technology. Another incentive device are innovation prizes (for example, 'big cash' awards). ${ }^{144}$ These may be particularly relevant where a specific problem is to be solved, but where the aimed-at product is unlikely to be patentable, for instance, because it relies largely on existing technology. ${ }^{145}$ Yet another option is for the state to create a fund that rewards research on topics of public significance, where the patent system, for lack of a lucrative market, does not create such an incentive. ${ }^{146}$ The various incentive measures mentioned play a role primarily in the sphere of applied science. Their role diminishes as pure or basic science - the hallmark of the university - gains significance. ${ }^{147}$

non-profit sector': Idea Consult and others, 'Support for Continued Data Collection and Analysis concerning Mobility Patterns and Career Paths of Researchers', prepared for European Commission, August 2013, 70.

${ }^{141}$ Research bodies linked to a university are subsumed under the heading 'university'.

${ }^{142}$ This has been explained at subs 2.2 above.

${ }^{143}$ See James Love and Tim Hubbard, 'Prizes for Innovation of New Medicines and Vaccines' (2009) 18 Annals of Health Law 155, 157.

${ }^{144}$ See ibid 186 (' $[T]$ he use of prizes to reward innovation would expand access and increase investments in areas where innovation is most important').

${ }^{145}$ See Bruce G Charlton, 'Mega-Prizes in Medicine: Big Cash Awards May Stimulate Useful and Rapid Therapeutic Innovation' (2007) 68 Medical Hypotheses 1, 2. However, innovation prizes are not 'without problems'. Hence, 'the market value of useful inventions would typically be far greater than any prize that could be offered'. Furthermore, '[j]uries [are] not immune to the effects of outright bias, capture, cognitive dissonance, lobbying, and "marketing"': B Zorina Khan, 'Inventing Prizes: A Historical Perspective on Innovation Awards and Technology Policy' (2015) 89 Business History Review 631, 660.

${ }^{146}$ Thomas Pogge has proposed such a model at the global level with regard to neglected diseases: Thomas W Pogge, 'Human Rights and Global Health: A Research Program' (2005) 36 Metaphilosophy 182.

${ }^{147}$ It is usually considered that pure or basic research leads to applied research, which then, through development, leads to innovation. This, the linear model of innovation, is notably set out in Vannevar Bush, 'Science: The Endless Frontier' (1945) 48 Transactions of the Kansas Academy of Science 231. It has, however, also been contended that there is research straddling basic and applied research: see Donald E Stokes, Pasteur's Quadrant: Basic Science and Technological Innovation (Brookings Institution Press 1997) (this being the essential thesis of Stokes' book). 
In private companies, maximum freedom for the employer, and also for employees vis-à-vis their employer, makes good sense. ${ }^{148}$ The state should respect and facilitate such creative freedom in its research and development policies for the private business sector. Private companies, however, pursue commercial rather than public interest objectives. This justifies lower levels of state protection for freedom of science in private companies compared with non-university research institutes and universities. Yet, intervention by the state might readily conflict with other important values. It might notably run counter to free-market principles.

In the case of non-university research institutes, the creator - that is, the state in respect of public institutes - has a clear role in the determination of the fields of research assigned to specific institutes. Other than in the case of universities, the research will often be more instrumentally defined - that is, directed towards a particular socio-economic purpose. However, this does not mean that these institutes do not undertake some pure science as well. The authorities of an institute will concretise the research agenda and may expect employees to take an active part in pursuing the agenda. ${ }^{149}$ For the rest, however, especially as regards the use of methods, the freedom of scientists in non-university research institutes should enjoy wide protection.

In the case of universities and research bodies linked to universities, research should predominantly be pure and disinterested. The state is not precluded from also broadly suggesting and even funding specific topics of research. Beyond that, however, institutional autonomy, individual academic freedom, self-governance, collegiality and tenure need to be strictly observed. While state supervision of universities is important, this should clearly reflect a 'hands-off' approach with the state intervening only in instances where academia clearly is in dereliction of its duties. However, all state supervision and intervention in itself must be subject to the control of the courts. The university as 'the conscience and critic of society' enjoys a special status justifying special protection of freedom of enquiry. ${ }^{150}$ Gerhard Casper, a former president of Stanford University, accordingly underlines that the great advantage of the research-intensive university in contributing to innovation is its ability 'to set agendas and remain open to chance and serendipity in research'. ${ }^{151} \mathrm{He}$ explains that if the research-intensive university were to be

\footnotetext{
${ }^{148}$ It has been stated that " $[\mathrm{t}$ ]he characteristic ... that enable[s] [companies] to attain ... diversity in [their] product line is a policy of what has generally come to be called "intrapreneurship". The basic idea is to allow employees of large corporations to behave within the company as they would as individual entrepreneurs in the outside world': Henry Petroski, The Evolution of Useful Things (Vintage Books 1994) 83-84.

${ }^{149}$ See Barendt (n 43) 37 (' $[\mathrm{T}]$ here can surely be nothing wrong in the authorities at a specialist institute ... of government ... determining what it wants to research and directing its employees how to set about it'). This is also true for private companies: ibid.

${ }^{150}$ See, for example, Jonathan Wolff, 'Britain's Bullied Universities Should be Speaking Truth to Power', The Guardian, 10 April 2018, https:/www.theguardian.com/education/2018/apr/10/britain-bullied-universities-jonathan-wolff ('I fully endorse the idea that universities should be the conscience and critic of society'). See further New Zealand's Education Act 1989 (1989 No 80), s 162(4)(a)(v) (Universities 'accept a role as critic and conscience of society'). See also subs 2.2 above, where this point was made from the perspective of differences between the concepts of freedom of science and academic freedom. The discussion there pointed out differences in the operation of individual freedom rights, self-governance, collegiality and security of employment in different types of entity.

${ }^{151}$ Gerhard Casper, The Winds of Freedom: Addressing Challenges to the University (Yale University Press 2014) 177.
} 
subordinated to the pressures of business product development or governmental industrial policy, it would lose the advantage inherent in 'its commitment to the endless process of inquiry, the search to know'. ${ }^{152}$

Interestingly, the above scheme entailing lower levels of freedom of enquiry in the research and development (R\&D) sector and highest levels in universities is also supported by economic arguments. Partha Dasgupta and Paul David explain that the symbiotic relationship between the $R \& D$ and university sectors crucially depends on respecting the distinct rules and reward systems of each. ${ }^{153}$ Justifiably lower levels of freedom of enquiry (choosing research topics, publishing or claiming 'ownership' of research findings, and so on) in the R\&D sector are offset by higher wages. Traditionally far lower wages in universities, in turn, need to be compensated for by high levels of freedom of enquiry, enabling researchers to develop a reputation, this being a vital reward for university scientists. ${ }^{154}$ Dasgupta and David thus underline that 'the taste for the lifestyle of science' of university scientists needs to be respected, which requires governments, inter alia, to subsidise pure, free science at high levels. ${ }^{155}$ Not respecting their taste for science would damage the economic structure of science, as many brilliant researchers would leave the pure science sector, resulting in largely 'privatised' science and a lack of fundamental research sustaining long-term economic growth. ${ }^{156}$

The REBSPA requires the research in entities belonging to all three groups to protect the human dignity of all those subject to scientific experimentation or who may suffer from abuse or adverse effects of science and its applications. It also requires states to take measures to ensure that the benefits flowing from scientific activity in any entity are distributed as widely as possible and on a non-discriminatory basis in society. These two points are crucially important. However, as they do not constitute the focus of this article, they will not be further commented on in their own right here.

\footnotetext{
152 ibid 178. Franz Himpsl has devised an interesting model in terms of which science may occur in one of four forms: (i) as politicised science, with the goals and methods predefined; (ii) as science for the production of insights ('Wissenschaft als Erkenntnismaschine'), with the goals, but not the methods predefined; (iii) as science as a game ('Wissenschaft als Spiel'), with neither goals nor methods predefined, but yet led by a sense of priorities; and (iv) as maximally free science, with neither goals nor methods predefined and led by pure curiosity: Franz Himpsl, Die Freiheit der Wissenschaft: Eine Theorie für das 21. Jahrhundert (JB Metzler/Springer 2017) 141-95 (in German). In terms of this model, science in universities (unless it involves commissioned research) falls largely within the sphere of science as a game. There must, however, also be ample room for maximally free science. Commissioned research in universities, much or most science in non-university research institutes, and essentially all research in private companies would be examples of science for the production of insights. Science should never be politicised science.

${ }^{153}$ Partha Dasgupta and Paul A David, 'Toward a New Economics of Science' (1994) 23 Research Policy 487, 518.

154 ibid 513-15.

155 ibid 515.

156 ibid 515, 518. For a similar argument, see Matthew S Clancy and GianCarlo Moschini, 'Incentives for Innovation: Patents, Prizes, and Research Contracts' (2013) 35 Applied Economic Perspectives and Policy 206, 218-19 (academic freedom and tenure in universities are a necessary reward). For empirical evidence demonstrating that scientists trade off wages for freedom of enquiry in choosing a career in the university rather than the R\&D sector, see Scott Stern, 'Do Scientists Pay to Be Scientists?' (2004) 50 Management Science 835.
} 


\subsection{The Role of the State, Legislation and Its Limits}

The adoption of framework legislation for the science sector is crucial. A wide-ranging regulation of the science sector by the state at the mere executive or administrative level lacks democratic legitimacy and violates the rule of law. ${ }^{157}$ Legislation in the sphere of science should, firstly, guarantee rights; secondly, lay down rules of conflict resolution; and, thirdly, stabilise the science sector financially and organisationally. ${ }^{158}$ Such legislation will have to establish a balance between positive and negative state obligations under the REBSPA that duly protects scientific and academic freedom. It is the duty of the courts to insist on rectification where this balance has not been achieved. In other words, the courts are tasked in this sense with constitutionally safeguarding that legislation is 'adequate for science' - and, therefore, complies with human rights.

Specifically as regards the guaranteeing of rights, legislation needs to provide protection for scientific and academic freedom. In accordance with what has been stated under the previous heading, protection levels will be lower in private companies, but very high in universities, with those in non-university research institutes somewhere in the upper half of this scale. With this in mind, individual scientific and academic freedom rights need to be defined. Furthermore, in universities, ensuring that institutional, faculty and departmental decisions on science are 'adequate for science' needs to be guaranteed by detailing the requirements of selfgovernance and collegiality. ${ }^{159}$ However, the concept of 'adequacy for science' plays a role also in non-university research institutes. Hence, certain rights of participation in governance for scientists need to be applicable in this context as well. As a procedural safeguard of scientific or academic freedom, employment security - tenure in the case of universities - should be protected. Legislation must protect the human dignity of all those 'exposed to' science and outline appropriate claims to share in scientific progress. Legislation should set out all the various entitlements and specify remedies and procedures to enforce these. The courts must have the competence to enforce these entitlements. ${ }^{160}$

Although legislative and other state measures must provide a framework for organising science, state action should, beyond that, reflect a high level of restraint in regulating the field. This is a consequence of the fact that 'the administrative apparatus of a democratic state is not

\footnotetext{
${ }^{157}$ It is trite that in the state based on the rule of law, all state action needs to be buttressed by formal law. Such formal law (legislation), which is to be adopted by a democratically elected parliament, needs to take all fundamental decisions (guiding principles, rights, limitations, enabling framework, organisation, finances, etc) regarding the sector concerned. On the requirement of legislation specifically as it relates to freedom of enquiry in universities, see Klaus D Beiter, Terence Karran and Kwadwo Appiagyei-Atua, 'Academic Freedom and Its Protection in the Law of European States: Measuring an International Human Right' (2016) 3 European Journal of Comparative Law and Governance 254, 258-60, 300-327.

${ }^{158}$ See Martin Schulte, 'Grund und Grenzen der Wissenschaftsfreiheit' in Kultur und Wissenschaft (Veröffentlichungen der Vereinigung der deutschen Staatsrechtslehrer, Vol 65, De Gruyter Recht 2006) 110, 124 (in German) (identifying these three functions for legislation in the sphere of science).

${ }^{159}$ On the term 'adequacy for science', see n 18 and accompanying text.

${ }^{160}$ On the requirement of legislation as it relates to academic freedom, see Beiter, Karran and Appiagyei-Atua (n 157) 258-60, 300-327.
} 
well suited to the management of scientific research'. ${ }^{161}$ Bureaucracy is inimical to risk, but risk is a prerequisite for science. Creativity and accountability are mutually exclusive concepts. ${ }^{162}$ It has been stated correctly that:

[o]verall, a 'model of regulated self-regulation' thus becomes visible, deducing its adequacy for science from the 'correct' mix of instruments, entailing legislation in the field of science exhibiting a more pronouncedly procedural character and [only] a medium level of complexity or density of regulation and, on an equal footing, the application of sets of rules produced by the scientific fraternity itself. ${ }^{163} \ldots$ It is this self-regulation by the scientific fraternity which becomes the idea of freedom of science. ${ }^{164}$

Framework legislation should thus provide a basis for the installation of relevant bodies and structures of science. Ultimate competence for regulation and decision making in the science sector should be assigned to the scientific fraternity itself (and this means active teachers and researchers rather than unelected, executive university or science 'managers'), as represented in these bodies and operating within these structures. The more decentralised these functions are, the better. Most decisions are best left to individual universities and research institutions. The essential body of norms for science would therefore largely comprise written and unwritten statutes, by-laws, procedures, rules and conventions originating formally and informally within the scientific community. The legitimacy of this body of norms is (to be) grounded in the stated framework legislation. Again, the courts must be competent to enforce scientific and academic freedom by putting the government in its place whenever it transgresses the boundaries of its powers. However, the scientific fraternity itself is also subject to the courts' review competence, as its own normative, administrative or adjudicative acts might not always live up to the demands of the various elements of the REBSPA, including scientific and academic freedom.

Clearly, the state is obliged 'to facilitate and to promote the free exercise of science and the transmission thereof to subsequent generations through the provision of personnel, financial and organisational resources'. ${ }^{165}$ Where the state has established universities, it is also required financially to ensure that free research and teaching can take place in these institutions. ${ }^{166}$ Basic (that is, block) institutional research funding needs to be substantially increased and competitive funding (through national research assessment exercises and grant competitions) substantially reduced. Competitive funding favours 'fashionable' topics ${ }^{167}$ and, therefore, tends to corrupt

\footnotetext{
${ }^{161}$ John Ziman, Science in Civil Society (Imprint Academic 2007/Andrews UK 2016) Ch 11.

162 ibid ('[The state's] bureaucratic norms favour routine and reject risk. Its accent on accountability cannot be harmonised with the uncertain promises of experimentation').

${ }^{163}$ Schulte (n 158) 125.

164 ibid 114.

${ }^{165}$ Hochschul-Urteil [University Judgment] (n 120) para 132.

${ }^{166}$ Ute Mager, 'VI. Wissenschaft und Kunst, § 166 Freiheit von Forschung und Lehre' in Josef Isensee and Paul Kirchhof (eds), Handbuch des Staatsrechts der Bundesrepublik Deutschland, Band VII - Freiheitsrechte (3rd edn, CF Müller 2009) 1075 para 42 (in German).

${ }^{167}$ See, for example, Li Bennich-Björkman, 'Has Academic Freedom Survived? An Interview Study of the Conditions for Researchers in an Era of Paradigmatic Change' (2007) 61 Higher Education Quarterly 334, 348-52 (whose interview study of academic staff in Swedish universities confirms this).
} 
'scientific' or 'academic intuition'. States should exercise restraint in 'pushing' science through time limits and incentive instruments offering rewards. Notably in universities, science can - in fact, must - do largely without such incentive instruments. ${ }^{168}$ This is what we meant above by 'choice of the wrong regulatory instruments'. ${ }^{169}$ The prospect for these scientists to enjoy reverence in the scientific community is more than sufficient incentive. ${ }^{170}$ Mathias Binswanger remarks on over-incentivisation generally that the stylised competitions in science for publications, citations, and third-party projects (financing) have caused the emergence of 'more and more nonsense in the form of publications and projects'. ${ }^{171}$ In his view, the effect of the system is to crowd out intrinsic motivation, unconventional approaches, individual talent, and basic research. Quantity replaces quality, form replaces content, and bureaucracy replaces research. ${ }^{172}$

Consequently, the arrangements suggested under this heading effectively make the legislature the structural, the scientific fraternity the everyday, and the courts the final guardian of the science system. Insofar as pure science is concerned, the government's role is to focus on financing, providing, encouraging, mediating and supervising - within the bounds of the law, which, in itself, must comply with human rights - and thus be 'adequate for science', as understood here.

\section{Corporatism in Science versus Scientific and Academic Freedom}

Caveat 3 (Corporatism v Freedom): One should not accord legitimacy to corporatism in science to advance socio-economic progress. Enforcing a focus on science 'useful to the economy', through methods drawing on a false analogy between scientific endeavour and doing business, depletes science of most of its value. Research management is a flawed concept. Scientific or academic freedom remains the best guarantor of scientific progress in the interest of society at large.

The previous section underlined the undesirability of government's overregulation of the science sector. It made suggestions in respect of an 'adequate' framework for organising or regulating science. This section focuses on the principal ideology underlying present-day overregulation in science - corporatism. It explains briefly what corporatism entails and how

\footnotetext{
${ }^{168}$ For example, state subsidy for articles published in journals appearing on a government list of 'accredited' journals, ratings (linked to funding) awarded to researchers, performance bonuses paid by universities, promotion, etc. This is not to deny the role of patents or innovation prizes, as discussed in subs 3.2 above, granted for actual innovative solutions in the field of applied research.

${ }^{169}$ See n 119 and accompanying text.

${ }^{170}$ Generally of incentivisation strategies in (UK) science, Philip Moriarty states that they 'run counter to the ethos of publicly funded academic science, and significantly compromise the societal value (and trustworthiness) of university research, but they are, perhaps counter-intuitively, of economically questionable value': Philip Moriarty, 'Science as a Public Good' in John Holmwood (ed), A Manifesto for the Public University (Bloomsbury Academic 2011) 56, 57 (emphasis omitted). Further, '[t]he indirect incentivization pathway is crucial: university management is entirely complicit in the erosion of the ethos of academic science': ibid 64. See also the interesting article on the topic by Edwards and Roy (n 10).

${ }^{171}$ Mathias Binswanger, 'Excellence by Nonsense: The Competition for Publications in Modern Science' in Sönke Bartling and Sascha Friesike (eds), Opening Science: The Evolving Guide on How the Internet Is Changing Research, Collaboration and Scholarly Publishing (Springer 2014) 49, 65.

172 ibid 65-67.
} 
this fails scientific progress in the interest of society at large. It shows that the corporatist orientation of the sector is not 'adequate for science'.

\subsection{The Ideology of Corporatism and 'Useful' Science}

Corporatism has become a central guiding principle for state development of higher education and science in universities and research institutions. The author and colleagues comprehensively reviewed the state of the legal protection of academic freedom in 28 European countries recently, to find not only that this is abysmal, but also that it has deteriorated over the last two decades or so. ${ }^{173}$ Whereas most countries formally ascribe to academic freedom in their constitutions and laws, a reading of the fine print tells a very different story. Academic freedom has in many cases become an empty phrase. Legislative reforms have paved the way for state control of science. Instead of the various parameters of individual academic freedom, institutional autonomy, self-governance and tenure having been woven into the fabric of the legislative framework as a whole, one may notice provision having been made for what Margeritha Rendel calls 'financial' and 'managerial attacks' on higher education and science. ${ }^{174}$ These 'attacks' are intended to realise economic growth as the sole end of higher education and science. 'Financial attacks' would entail deliberately underfunding the sector, placing the focus on competitive funding, and encouraging institutions to obtain large sums of finance for contract research performed on behalf of the government or industry. ${ }^{175}$ 'Managerial attacks' refer to top-down forms of governance in universities and research institutions and the adoption of 'an audit culture', entailing the regular measuring of performance of staff and institutions by 'counting output' ${ }^{176}$ In a

\footnotetext{
${ }^{173}$ We have reported on this in a few journals: see, for example, Klaus D Beiter, Terence Karran and Kwadwo Appiagyei-Atua, "Measuring" the Erosion of Academic Freedom as an International Human Right: A Report on the Legal Protection of Academic Freedom in Europe' (2016) 49 Vanderbilt Journal of Transnational Law 597, and our study mentioned in $\mathrm{n} 157$. In a second phase, we intend to look at the factual protection of academic freedom (inter alia, as a result of institutional, faculty and/or departmental regulations, policies and customs) in the same countries, relying on a survey: see https://www.surveymonkey.com/r/AcademicFreedomSurvey. Our findings confirm the perception among many academic leaders in Europe. Dieter Lenzen, former spokesperson for the German universities at the Conference of Rectors of Higher Education Institutions, thus states: 'It is ... obvious that individual freedom for professors and students has been significantly limited by the Bologna Process': Dieter Lenzen, University of the World: A Case for a World University System (Springer 2015) 31. Arne Jarrick, former Secretary-General for the Humanities and Social Sciences at the Swedish Research Council, states: 'It is ... becoming increasingly clear how the praise of free basic research is being reduced to nothing more than accolades': Arne Jarrick, 'The Scientific Mission and the Freedom of Research' in Rider, Hasselberg and Waluszewski (n 11) 53, 58.

${ }^{174}$ Margherita Rendel, 'Human Rights and Academic Freedom' in Tight (n 53) 74, 84-85.

${ }^{175}$ See, for example, David L Lewis, Science for Sale: How the US Government Uses Powerful Corporations and Leading Universities to Support Government Policies, Silence Top Scientists, Jeopardize Our Health, and Protect Corporate Profits (Skyhorse Publishing 2014) Prologue xix ('[E]normous resources are being invested to create the illusion of science needed to protect government policies and industry practices').

${ }^{176}$ In this respect, it is also spoken of 'the new public management' of science (focusing on the UK, see, for example, Rebecca Boden and others, Scrutinising Science: The Changing UK Government of Science (Palgrave Macmillan 2004) 56-72), or 'the new managerialism' in universities (also focusing on the UK, see, for example, Rosemary Deem, Sam Hillyard and Mike Reed, Knowledge, Higher Education, and the New Managerialism: The Changing Management of UK Universities (Oxford University Press 2007) notably 1-28).
} 
nutshell, corporatism in science therefore means enforcing a pure economic rationale for science through methods drawn from the business world, in the form of manifold incentives, hierarchical governance and quality audits. ${ }^{177}$

It appears that in many governments there is a perception that comprehensive state action, implemented through universities and research institutions being kept on a short leash, is the recipe for advancing science, securing its benefits to society, and enhancing socio-economic progress. Nobel Literature laureate John Coetzee points out that the university traditionally was outside and above the everyday political scrum. This gave it a degree of disengagement, independence and self-determination, which allowed its members to engage with questions of the public good in a non-partisan and critical way. ${ }^{178}$ Meanwhile, however, the state exerts a tight grip over teaching and research. Referring to British universities in this context, Eric Barendt observes that ' $[t]$ he independence of ... universities has been substantially limited in the last thirty years, so that now only lip-service may be paid to their autonomy'. ${ }^{179}$ Universities have become 'the arm of national economic policy' ${ }^{180}$ Universities are to contribute to the gross national product (GNP). The only two forms of justification for state funding for universities these days are manpower planning and narrowly defined benefits of research, particularly medical, technological and economic benefits. ${ }^{181}$

Recently, a senior manager in a South African university aired his view to the author that if one were to give academics freedom, this would just lead to chaos. ${ }^{182}$ The emergence of the 'authoritarian' or 'disciplinary' university - in South Africa as elsewhere - is not coincidental, but clearly intended. Another high-profile South African university manager in a talk juxtaposed 'academic freedom' and 'relevance' as 'the two options available in research', the insinuation being that academic freedom grants academics a right to do what is 'irrelevant', and that what is relevant should not be determined by academics themselves but by the state and university management. ${ }^{183}$ Academic freedom does not, of course, include a right to do what is 'irrelevant'. However, it implies the right of academia, as opposed to government or university management, to define relevance. The latter have come to interpret 'relevance' as practical or economic usefulness. This clearly sets the road to dictatorship in science - a market-fundamental dictatorship in science.

\footnotetext{
${ }^{177}$ There exists such a vast body of literature here on what is termed corporatism in higher education and science that it can hardly be cited properly; yet, some of it is mentioned at n 319 . One may point out that most of the literature is 'non-legal' in nature.

${ }^{178}$ John M Coetzee, 'Foreword' in John Higgins (ed), Academic Freedom in a Democratic South Africa: Essays and Interviews on Higher Education and the Humanities (Wits University Press 2013) xi, xii-xiii.

${ }^{179}$ Barendt (n 43) 67.

${ }^{180}$ Jill Blackmore, 'Globalisation: A Useful Concept for Feminists Rethinking Theories and Strategies in Education' in Nicholas C Burbules and Carlos Alberto Torres (eds), Globalisation and Education: Critical Perspectives (Routledge 2000) 133, 134.

${ }^{181}$ Stefan Collini, What Are Universities For? (Penguin Books 2012) Ch 5.1. In support of this observation, see also the various sources mentioned at $\mathrm{n} 319$.

${ }^{182}$ Unreferenced for reasons of confidentiality.

${ }^{183}$ Also unreferenced for reasons of confidentiality.
} 
Most commonly, the reaction of academics to this ideology is to keep quiet and acquiesce in this, what may be termed a 'dispossessive' model of the university and of science, designed for them (and society) by the state - and, after all, also by university management. ${ }^{184}$ However, increasingly, academics - living up to their role as immediate guardians of a system 'adequate for (university) science' - are becoming more vocal in contesting that ideology. The Manifesto: Reclaiming Our University, a document of 2016 prepared by staff and students of the University of Aberdeen, Scotland thus finds: ${ }^{185}$

We stand at a pivotal moment in the long history of our university, a fork in the path that offers two ways forward. One is to follow the business model of higher education to its logical conclusion, in a competition for students, research funding and ratings that values constant change as an end in itself. The other is to rediscover the civic purpose of the university as a necessary component of the constitution of a democratic society, with the responsibility for educating its citizens and furnishing them with the wisdom and understanding that will enable them to fashion a world fit for future generations to live in.

In 1997, UNESCO adopted the Recommendation concerning the Status of Higher-Education Teaching Personnel - a code regulating the profession of teaching and research in higher education and, by way of such regulation, seeking to enhance the quality of the higher education system. Overall, the Recommendation is a commendable instrument. Although not legally binding like a convention, it has 'a normative character in [its] intent and effects'. ${ }^{186}$ Politically, states are not free to ignore its provisions on academic freedom, institutional autonomy, self-governance, collegiality and tenure. ${ }^{187}$ Yet, many observers would now agree that the Recommendation, in its present form, would be unlikely to muster the support of a majority of states today. This is

\footnotetext{
${ }^{184}$ See Paul Taylor, 'Humboldt's Rift: Managerialism in Education and Complicit Intellectuals' (2003) 3 European Political Science 75, 75 (referring to 'supinely acquiescent academics'). It has, in fact, been argued that the new managerial pressures on academics have caused them to conform with the new rules and to engage in large-scale self-censorship: Joanna Williams, Academic Freedom in an Age of Conformity: Confronting the Fear of Knowledge (Palgrave Macmillan 2017) 56-58.

${ }^{185}$ The Manifesto: Reclaiming Our University (n 41) para 2. There appears to be a spreading 'reclaiming movement' in many universities worldwide. A number of publications have proposed manifestos accordingly: see, for example, Willem Halffman and Hans Radder, 'The Academic Manifesto: From an Occupied to a Public University' (2015) 53 Minerva 165, or 'The Manifesto' in Michael Bailey and Des Freedman (eds), The Assault on Universities: A Manifesto for Resistance (Pluto Press 2011) 177.

${ }^{186}$ Yves Daudet and Kishore Singh, The Right to Education: An Analysis of UNESCO's Standard-Setting Instruments (UNESCO 2001) 45 (thus describing the nature of UNESCO Recommendations).

${ }^{187}$ See the following provisions of the UNESCO Recommendation 1997 (n 44) dealing with these aspects: paras 17-21 (institutional autonomy), paras 27-29 (academic freedom), paras 31-32 (self-governance and collegiality), paras 45-46 (security of employment, including tenure). UNESCO Recommendations are 'politically' binding. Member states must submit them to the competent national authorities and report on their implementation to UNESCO: Constitution of the United Nations Educational, Scientific and Cultural Organization (1945) (entered into force 4 November 1946) 4 UNTS 275, art IV(4), (6), respectively. In the light of arts 22 and 23 of the ICESCR and the reference in the 1997 Recommendation to art 13(2)(c) of the ICESCR on the right to higher education in its Preamble, the Recommendation may even, as a subsequent practice in the application of the ICESCR revealing the parties' intention, be considered related to 'the context' of the relevant terms of the ICESCR for purposes of interpreting the Covenant: VCLT (n 8) art 31(3)(b).
} 
so because the idea of the university as a business producing for society has meanwhile 'colonised' the minds of policy makers in higher education and science. Teaching and research are to be useful. In 2003, Charles Clarke, then UK Secretary of State for Education, remarked that the state should only fund higher education teaching and research with a 'clear usefulness'. He said, 'I don't mind there being some medievalists around for ornamental purposes, but there is no reason for the state to pay for them'. ${ }^{188}$ Science - thus the buzzword these days - should demonstrate 'impact'. Accordingly, in attempting to achieve such usefulness or impact, trust as a foundational principle of teaching and research in universities (as well as of other research serving the public interest) has been surrendered to that of control and management. ${ }^{189}$ Performance control in science is bound to destroy trust. This is a natural consequence of the 'value incongruence' between the tasks of scientists, which are highly uncertain, and quality management, which uses 'inappropriately' deterministic performance standards. ${ }^{190}$

\subsection{Research Management as a Flawed Concept}

As for research, the new ethos of distrust is reflected in control and management of researchers and their circumstances, of the research content, of the research process, and of the research purposes. For many reasons, however, research management is a flawed concept.

Firstly, research management consumes enormous resources, finance-, energy-, and timewise. The most significant increase in appointments in universities these days, for example, may often be noted for management (rather than academic) staff. ${ }^{191}$ States therefore invest more and more money in research management rather than in research itself. This is odd, to say the least. Moreover, publication duties, writing funding applications, preparing budget plans and reports, obtaining ethical clearance, progress reporting, performance appraisals ('audits') and administrative red tape relating to research nowadays consume ever more time and energy, which are not available for actual research. It has been observed that ' $[t]$ he push

\footnotetext{
${ }^{188}$ See 'Clarke Lays into Useless History', Times Higher Education, 9 May 2003, https://www.timeshighereducation. com/news/clarke-lays-into-useless-history/176578.article.

${ }^{189}$ See, for example, Deem, Hillyard and Reed (n 176) 25 (“"institutionalized distrust", rather than "regulated autonomy", has come to define the contemporary condition and practice of [academics]'); Chris Holligan and Ibrahim Sirkeci, 'Measuring Academic Research Performance through Audit at the Expense of Trust: Exploring the 21st Century University', Border Crossing, Transnational Press London, vol 2011(1104), December 2011, 45, 45 (audit culture and quality control 'diminish ... a collegiate culture of trust and pursuit of truth'); Łukasz Sułkowski, 'The Culture of Control in the Contemporary University' in Michał Izak, Monika Kostera and Michał Zawadzki (eds), The Future of University Education (Palgrave Macmillan 2017) 85, 85 (in university management nowadays, 'the culture of control and the culture of evidence play key roles').

${ }^{190}$ Michael Power, 'Research Evaluation in the Audit Society' in Hildegard Matthies and Dagmar Simon (eds), Wissenschaft unter Beobachtung: Effekte und Defekte von Evaluationen (VS Verlag für Sozialwissenschaften 2008) $15,15$.

${ }^{191}$ Hence, with regard to the UK, see Laurie Taylor, 'Laurie Taylor on Academics v Administrators', Times Higher Education, 28 May 2015, https://www.timeshighereducation.com/content/laurie-taylor-on-academics-vadministrators. See also Benjamin Ginsberg, The Fall of the Faculty: The Rise of the All-Administrative University and Why It Matters (Oxford University Press 2011) 204-05 ('managerial inflation at some schools has been truly astonishing ... [a] 20 percent or larger cut would ... have ... beneficial effect[s]').
} 
to make educational institutions more money-valuable ... is the primary driver of the loss of thought-time'. ${ }^{192}$ Academic freedom depends not only on the formal protection of the right to pursue research opposing the dominant money-value system, but it also requires the time to do so. ${ }^{193}$ The loss of thought-time threatens the social value of academic work. ${ }^{194}$ Quality research requires 'time and tranquillity'. 195

Secondly, research management seems not to produce any beneficial result. Creating financial incentives is seen as an important component of research management. Hence, in the United States, the Bayh-Dole Act of $1980^{196}$ - which subsequently had served as a model for similar legislation in many other countries - sought to fundamentally reform the relationship between university research and industrial innovation by giving universities extensive rights to exploit intellectual property rights with regard to innovative technologies. In their book Ivory Tower and Industrial Innovation, David Mowery and his colleagues, through a mix of historical research, economic analysis and case studies, demonstrate that the innovation that did result and flow into the market following the adoption of the Act would probably equally have done so without it. The much-praised Act seems not to be the key to explaining the contribution of universities to the US economy. ${ }^{197}$ Similarly, incentivising scholarly publishing has led to an exponential growth in the number of books, journals and articles being published. Yet, the amount of knowledge gained can hardly be said to have increased accordingly. It has been stated that ' $[0] n$ average the content of ... papers gets increasingly irrelevant, meaningless, and redundant' ${ }^{198}$ This is because scholars turn their thoughts away from scientific problems towards the

192 Jeff Noonan, 'Thought-Time, Money-Time, and the Temporal Conditions of Academic Freedom' (2015) 24 Time \& Society 109, 113.

193 ibid 115.

194 ibid 114-15.

${ }^{195}$ Walter Berka, 'Wissenschaftsfreiheit an staatlichen Universitäten: Zur Freiheit und Verantwortung des Wissenschaftlers' in Karl Weber and Norbert Wimmer (eds), Vom Verfassungsstaat am Scheideweg: Festschrift für Peter Pernthaler (Springer 2005) 67, 80 ('Zeit und Ruhe') (in German). Hence, whereas Dick Pels in 2003 had already called for 'the unhastening of science' (Dick Pels, Unhastening Science: Autonomy and Reflexivity in the Social Theory of Knowledge (Liverpool University Press 2003)), this has meanwhile, in reaction to scientific productivism, given rise to the so-called 'Slow Science' movement. See, for example, 'The Slow Science Manifesto', 2010, http://slow-science.org; René Boomkens, Topkitsch en slow science: Kritiek van de academische rede (Van Gennep 2008) (in Dutch); Olivier P Gosselain, 'Slow Science: La désexcellence' (2011) 1 Uzance: Revue d'Ethnologie Européenne de la Fédération Wallonie-Bruxelles 128 (in French); Isabelle Stengers, Another Science Is Possible: A Manifesto for Slow Science (Stephen Muecke tr, Polity Press 2018); Peter Weichhart, "Slow Science" versus Exzellenzstalinismus: Vom Nutzen wissenschaftlicher Reflexionen abseits der Evaluierungsbuchhaltung' in Marc M Seebacher, Raumkonstruktionen in der Geographie (Universität Wien Institut für Geographie und Regionalforschung 2012) 7 (in German).

${ }_{196}$ Patent and Trademark Law Amendments Act (Pub L 96-517, 12 December 1980).

${ }^{197}$ David C Mowery and others, Ivory Tower and Industrial Innovation: University-Industry Technology Transfer before and after the Bayh-Dole Act (Stanford University Press 2004). See also Kira R Fabrizio, 'University Patenting and the Pace of Industrial Innovation' (2007) 16 Industrial and Corporate Change 505 (presenting evidence to show that university patenting is hindering or slowing knowledge exploitation); Martin Kenney and Donald Patton, 'Reconsidering the Bayh-Dole Act and the Current University Invention Ownership Model' (2009) 38 Research Policy 1407 (arguing that, in the light of the failings of the Bayh-Dole model, patents should vest in the inventor, with the university entitled to share in returns; alternatively, that the invention should immediately be publicly available, through a public domain strategy, or mandatory non-exclusive licences to a patent). ${ }^{198}$ Binswanger (n 171) 62. 
process of submission, reviewing and publication. ${ }^{199}$ Current practices and norms in academic publishing 'contribute to destroying or crucially damage preconditions for original research', as more and better ('cutting-edge', as it is called) research in less and less time cannot be achieved. ${ }^{200}$ Nothing is more time-consuming than good research.

Thirdly, research management undermines scholarly integrity. Imad A Moosa, Professor of Finance in Australia, describes the devastating effect that 'publish or perish' (POP) - a central tool of research management - has on science. Furnishing impressive proof, he shows how the pressure to publish extensively in 'high-impact' journals following 'rigorous' peer review has not only resulted in researchers publishing papers of deteriorating quality, but also for them on a grand scale to fabricate data, plagiarise, self-plagiarise, salami-slice, republish the same content, report biasedly, manipulate results, commit misconduct with regard to authorship, and publish results that are not reproducible. ${ }^{201}$ The way forward, he suggests, 'is to abandon the POP culture'. ${ }^{202}$ Before its advent, academics enjoyed 'fairly secure academic freedom'. ${ }^{203}$ While most academics were teachers who did little research, only the best researchers published, their sole reward being recognition. 'There is nothing wrong with this model - it is division of labour that leads to efficiency'. 204

Fourthly, research management often violates scientific or academic freedom. To mention an example from the South African academic context, which is representative of similar interventionist practices in other countries: the South African government, in its zealous efforts to guarantee that science in universities will produce progress, maintains a list of 'accredited' journals (journals it considers 'appropriate'). For each article published in an 'accredited' journal, the government pays a subsidy to reward the relevant institution. ${ }^{205}$ Largely underfunded universities compel their academic staff, up to a percentage, to rely on this income to pay for their own research activities. In practice, this means that staff who publish in 'non-accredited' journals will effectively not have sufficient funds available to attend conferences or pursue other academic activities that cost money. This constitutes a serious violation of academic freedom not only by universities but also the government, which must accept responsibility for the perverse consequences of the system it has installed. Under the UNESCO Recommendation concerning the

\footnotetext{
${ }^{199}$ Lawrence (n 10) R584. 'The current "publish or perish" culture in academia is arguably impeding the discovery process': Brianne Kent, 'Why Scientists Should Stop Publishing', University World News, Issue No 317, 25 April 2014, http://www.universityworldnews.com/article.php?story=20140424173116328.

${ }^{200}$ Li Bennich-Björkman, 'Down the Slippery Slope: The Perils of the Academic Research Industry' in Rider, Hasselberg and Waluszewski (n 11) 125, 134.

${ }^{201}$ Imad A Moosa, Publish or Perish: Perceived Benefits versus Unintended Consequences (Edward Elgar 2018) Ch 4. It has been remarked sarcastically that for researchers to succeed in the world of publishing, they need to 'hype' their work, slice up findings as much as possible, simplify conclusions, complexify material, and hide results 'that do not fit with the story': Lawrence (n 10) R584. For a description of the 'derailing' of science in the Netherlands as a result of productivist science, see Frank van Kolfschooten, Ontspoorde wetenschap: Over fraude, plagiaat en academische mores (De Kring 2012) (in Dutch).

${ }^{202}$ Moosa (n 201) 181.

203 ibid.

204 ibid.

${ }^{205}$ Republic of South Africa, Government Notice No 188, 'Research Outputs Policy, 2015', Government Gazette, Vol 597, No 38552, 11 March 2015, para 5.
} 
Status of Higher-Education Teaching Personnel of 1997 there is a right to publish; this includes the choice of medium. ${ }^{206}$ Scholars must be trusted to know which journal is 'the right one' for their research findings. Any government or university regulation as to what constitutes a suitable medium of publication for a university researcher is unacceptable per se. The decision where to publish falls within the scientist's 'absolute freedom' lying beyond government or university powers. $^{207}$ What makes the situation worse is that the stated list is highly arbitrary. Just one example: only three of the top 15 journals worldwide in the field of 'international law' are included on the list. The Virginia, Yale, and Chicago journals of international law, for instance, do not feature on it, ${ }^{208}$ although many insignificant journals are included. Furthermore, assuming journals to have been accredited, an article of 80 pages in an internationally acclaimed journal counts for the same as a case note of 5 pages in an unknown journal. This is, of course, the likely result of having bureaucrats, disconnected from the inner workings of science, deciding questions relating to research.

Fifthly, an omnipresent state and ever-nagging research and teaching 'managers' tend to poison the atmosphere of freedom that should prevail in universities. This, in turn, impacts negatively on the motivation of staff. Among the academic staff of the increasingly corporate university motivation has dropped dramatically over the last two decades or so. For South Africa, for example, it has been found that the organisational culture of managerialism and performativity, and the huge assignment put to universities, for instance, in promoting economic productivity, have resulted in a severe burden being placed upon academic staff. ${ }^{209}$ The reason for the stress and demotivation is that academics are no more mere scholars, but perform labour in three different paradigms: a scholarly community, a bureaucracy and a corporation, each with its own duties, with duties among these often conflicting. ${ }^{210}$

Sixthly, finally and very importantly, the endeavour to 'manage the research imagination' - as Rebecca Boden and Debbie Epstein have described practices of applying various disciplinary processes in universities directed at enhancing scholarly performance and the production of

206 ' $[\mathrm{H}]$ igher-education teaching personnel should be free to publish the results of research and scholarship in books, journals and databases of their own choice': UNESCO Recommendation 1997 (n 44) para 12.

${ }^{207}$ On this space of 'absolute freedom', see n 120. It should be noted that also 'the protection of science' against predatory journals is not a legitimate reason for interfering with the absolute freedom granted to scientists in this context. The proliferation of predatory journals is the direct consequence of the over-incentivisation of scholarly publishing. If this were to be done away with, predatory journals would soon disappear.

${ }^{208}$ See Washington and Lee School of Law, Law Journal Rankings, https://managementtools4.wlu.edu/ LawJournals; North-West University, Department of Higher Education and Training (DHET) List of Approved South African Journals 2018, http://collections.nwu.ac.za/dbtw-wpd/textbases/accredited-journals/accred.html (both databases accessed on 6 October 2018).

${ }^{209}$ Charl C Wolhuter, 'From Teachers to Perfect Humboldtian Persons to Academic Superpersons: The Teaching and Research Activities of the South African Academic Profession' in Jung Cheol Shin and others (eds), Teaching and Research in Contemporary Higher Education: Systems, Activities and Rewards (Springer 2014) 277, 284. Stress experienced by South African academics is caused by 'the top-down management style ... and the heavy workload', academics 'spend[ing] an extraordinary amount of time on administrative tasks': ibid 284-85. ${ }^{210}$ See the illuminating discussion by Ruth Barcan on the topic: Ruth Barcan, Academic Life and Labour in the New University: Hope and Other Choices (Ashgate 2013) 69-139. She believes that ' $[\mathrm{t}] \mathrm{o}$ embody the multiple spirits of the contemporary university, one would have to be something of a monster: the scholar-bureaucrat-entrepreneur': ibid 91. 
useful results - severely constricts critical thought. ${ }^{211}$ Critical thinking cannot occur in circumstances where the realm of permissible research is narrowed down at the outset to what the economy will need and where hopelessly overworked and always accountable academics have no time for reflection. Boden and Epstein consider the constriction of critical thinking to have the following two manifestations: ${ }^{212}$

First, there is the limitation of the institutions themselves and their recasting of themselves as producers only of 'useful' knowledge. There is a structural adjustment (with all of its development economics connotations) here that renders institutions virtually incapable of facilitating critical research. Second, there is the accelerating transformation of academic labour into an atomised, post-Fordist research proletariat that is, for the most part, constitutionally incapable of critical imagination.

Cultural theorist Stuart Hall is reported to have said that ' $[\mathrm{t}]$ he university is a critical institution or it is nothing'. ${ }^{213}$ Cognisant of his words, the scenario described above, in its final significance, naturally points to the end of the university as we know it. It is, therefore, understandable if experts on universities doubt whether universities can survive as critical organisations in the current time. ${ }^{214}$ Consequently, corporatism damages science. Ultimately, scientific or academic freedom remains the best guarantor of scientific progress in the interest of society at large.

\section{The UNESCO Recommendation on Science and Scientific Researchers of 2017: Not Quite a Perfect Blueprint to Guide the Interpretation OF THE REBSPA}

Caveat 4 (Resolving Conflicts): One should not fail to appreciate the significance of threats to scientific and academic freedom. The UNESCO Recommendation on Science and Scientific Researchers of 2017 reflects such failure in various ways. It does not comment on the allpervasive 'impact agenda' ideology of science in research councils and universities. It does not resolve conflicts between scientific or academic freedom and peer review, ethical regulation

\footnotetext{
${ }^{211}$ Rebecca Boden and Debbie Epstein, 'Managing the Research Imagination? Globalisation and Research in Higher Education' (2006) 4 Globalisation, Societies and Education 223.

212 ibid 234.

${ }^{213}$ Quoted in Giroux (n 10) Ch 5.

${ }^{214}$ Rosemary Deem and Heather Eggins, 'The University as a Critical Institution? An Introduction' in Rosemary Deem and Heather Eggins (eds), The University as a Critical Institution? (Sense Publishers 2017) 3, 3. In the light of the description here, it is no wonder that books on universities these days - as their titles indicate - paint a cataclysmic picture of the state of higher education and science: Collini (n 181); Thomas Docherty, Universities at War (Sage 2014); Frank Furedi, What's Happened to the University? A Sociological Exploration of Its Infantilisation (Routledge 2016); Andrew McGettigan, The Great University Gamble: Money, Markets and the Future of Higher Education (Pluto Press 2013); Christopher Newfield, Unmaking the Public University: The Forty-Year Assault on the Middle Class (Harvard University Press 2008); Bill Readings, The University in Ruins (Harvard University Press 1997); John Smyth, The Toxic University: Zombie Leadership, Academic Rock Stars and Neoliberal Ideology (Palgrave Macmillan 2017); Susan Wright and Cris Shore (eds), Death of the Public University? Uncertain Futures for Higher Education in the Knowledge Economy (Berghahn Books 2017).
} 
and intellectual property rights. Nor does it address the vigorous entrepreneurialisation of universities or the accountability excess that inhibits scientific progress. It also does not grant to scientific and academic staff rights of participation in the governance of institutions of science.

The recently adopted UNESCO Recommendation on Science and Scientific Researchers of 2017, a reworked version of the 1974 Recommendation on the Status of Scientific Researchers, ${ }^{215}$ in its Preamble refers to Article 27(1) of the Universal Declaration of Human Rights of 1948. This protects, inter alia, everyone's 'right ... to share in scientific advancement and its benefits', which constitutes the predecessor of what subsequently became the REBSPA in Article 15(1)(b) of the ICESCR. In a way, the UNESCO Recommendation, which is a soft law instrument, may therefore be seen as an interpretation of the REBSPA in Article 15(1)(b). ${ }^{216}$ However, does it also adequately address scientific and academic freedom, one of the three pillars of the REBSPA? Does it achieve the balance between positive and negative state obligations under the REBSPA that would make the science system 'adequate for science'?

\subsection{The Recommendation's Key Areas and the Scientific and Academic Freedom Rights Protected}

In an annex to its Resolution of 13 November 2017 adopting the Recommendation, UNESCO summarises the ten key areas addressed by the Recommendation. These are:

- the responsibility of science towards the UN ideals of human dignity, progress, justice, peace, the welfare of humankind and respect for the environment;

- the need for science to interact meaningfully with society and vice versa;

- the role of science in national policy and decision making, and international co-operation and development;

- the promotion of science as a common good;

- inclusive and non-discriminatory work conditions and access to education and employment in science;

- the need for scientific conduct to be subject to universal human rights standards;

- balance between the freedoms, rights and responsibilities of researchers;

- the importance of scientific integrity and ethical codes of conduct for science and research and their technical applications;

- the importance of qualified scientific researchers for a sound and responsible science system; and

- the role of member states in creating an enabling environment for science and research. ${ }^{217}$

\footnotetext{
${ }^{215}$ UNESCO General Conference, Recommendation on the Status of Scientific Researchers, UNESCO Doc 18 C/Res 40 (1974).

${ }^{216}$ On the legal nature of the Recommendation, and its being related to 'the context' of art 15(1)(b) of the ICESCR for purposes of interpreting the Covenant, as contemplated by art 31(3)(b) of the VCLT (n 8), see nn 186-87 and accompanying text.

${ }^{217}$ UNESCO Recommendation 2017 (n 13) Annex.
} 
Which aspects of scientific and academic freedom are then recognised by the Recommendation? A scrutiny of the document reveals the following:

- Status (standing, working conditions): Scientific researchers should enjoy a status (standing, working conditions) which facilitates fulfilment of their duty towards achieving national and global science goals. ${ }^{218}$ This may be stated to presuppose the protection of scientific and academic freedom.

- Scientific freedom in a more generic sense: In the Preamble to the Recommendation, member states recognise that the 'open communication of the results, hypotheses and opinions - as suggested by the phrase 'academic freedom' - lies at the very heart of the scientific process, and provides the strongest guarantee of accuracy and objectivity of scientific results' ${ }^{219}$ They should institute procedures which entitle scientific researchers to 'the degree of autonomy appropriate to their task and to the advancement of science and technology'. Creativity of scientific researchers should be promoted 'on the basis of utmost respect for the autonomy and freedom of research indispensable to scientific progress'. ${ }^{220}$ The Recommendation emphasises that researchers should enjoy the right 'to work in a spirit of intellectual freedom to pursue, expound and defend the scientific truth as they see it, an intellectual freedom which should include protection from undue influences on their independent judgement'.221

- Specific scientific freedom rights of scientific researchers: The Recommendation recognises rights of scientific researchers to publish or communicate results, ${ }^{222}$ to share scientific data, ${ }^{223}$ and to have access to scientific information. ${ }^{224}$ Researchers should enjoy the right of conscientious objection - 'to withdraw from ... projects if their conscience so dictates'. ${ }^{225}$ There are further provisions on 'the principle of freedom of movement ${ }^{226}$ and rights related to freedom of association. ${ }^{227}$

- Employment security: Member states should develop employment policies that protect state employees against 'precariousness due to mobility or limited-duration contracts' ${ }^{228}$

\footnotetext{
218 ibid Preamble, para 1(e). See also ibid para 24(a) (member states should assure 'material assistance, moral support and public recognition' to scientific researchers).

219 ibid Preamble. As is clear from the discussion above, 'scientific freedom' would have been the correct term to use here: see subs 2.2 above.

${ }^{220}$ ibid para 10.

${ }^{221}$ ibid para 16(a)(i). See also ibid para 27(b) (member states' employment policies should ensure researchers 'are not subjected, merely by the nature of their work, to avoidable hardship').

222 ibid para 38. The right may be restricted, however. Restrictions must be 'strictly minimised, consistent with public interest and the right of $\ldots$ employers and fellow workers, ... and properly communicated as clearly as possible in writing in the terms and conditions of ... employment': ibid para 38(a).

${ }_{223}$ ibid para 16(a)(v) ('sharing of scientific data between researchers, to policy-makers, and to the public').

${ }^{224}$ ibid para 28 ('free access to international databases and journals, libraries and other sources of information').

225 ibid para 16(a)(iii).

${ }^{226}$ ibid para 11. See also ibid para 31 (member states 'should facilitate ... travel in and out of their territory').

227 ibid para 42 (It is considered 'desirable' that 'scientific researchers should associate to protect and promote their individual and collective interests'. Relevant organisations 'should have the right to support the justified claims of ... researchers').

${ }^{228}$ ibid para 27(c). The Recommendation, however, does not refer to tenure for academic staff, which is referred to in the UNESCO Recommendation concerning the Status of Higher-Education Teaching Personnel of 1997 (n 44) paras 45-46.
} 
- Certain rights of collegiality or participation: The Recommendation further grants to scientific researchers the right 'to contribute to the definition of the aims and objectives of the programmes in which they are engaged and to the determination of the methods to be adopted'. ${ }^{229}$ Participatory rights also exist in a broader national context. ${ }^{230}$

- Rights of employers, funders, institutions: Educational institutions are entitled to 'the necessary and proper independence'. ${ }^{231}$ Persons or institutions that employ, fund or govern researchers or research enjoy certain rights equivalent to those of scientific researchers. These rights, however, must 'not impede on the scientific researchers' exercise of ... rights'. ${ }^{232}$

Consequently, on the above account the Recommendation includes quite a wide array of rights. The various rights implicate state duties at the levels of respecting, protecting and fulfilling rights. Except for very few provisions - notably paragraph 16(b) on the rights of employers, funders and institutions - the other provisions mentioned above were already present in an almost identical form in the 1974 instrument. However, what makes the situation rather critical from the perspective of scientific and academic freedom in the case of the new version of the Recommendation is that the latter introduces certain novel aspects with clear implications for scientific and academic freedom (such as peer review, ethics codes and committees, protection of confidential personal data, and so on), without providing sufficient safeguards..$^{233}$

The Recommendation does not always employ clear rights language. For example, it calls a right a 'principle', ${ }^{234}$ or it states that granting a certain right is 'desirable'. ${ }^{235}$ Unlike the 1997 UNESCO Recommendation concerning the Status of Higher-Education Teaching Personnel, the 2017 Recommendation does not contain a provision stating that scientific researchers 'should enjoy those internationally recognised civil, political, social and cultural rights applicable to all citizens', then enumerating some of these rights. ${ }^{236}$ Nor does it contain a full definition of scientific or academic freedom. ${ }^{237}$

\subsection{Scientific and Academic Freedom Play only a Secondary Role}

The identification of the Recommendation's ten key areas in the Annex to the adopting resolution, together with a holistic reading of the Recommendation, demonstrate that scientific and

\footnotetext{
${ }^{229}$ UNESCO Recommendation 2017 (n 13) para 16(a)(ii).

${ }^{230}$ See ibid para 8 ('opportunities for scientific researchers to participate in developing national science ... policy'); para 16(a)(iv) (right 'to contribute constructively to the fabric of science ... and the promotion of science $\ldots$ in the ... country').

231 ibid para 14.

232 ibid para 16(b)(i). Such persons and institutions must 'facilitate the exercise of ... rights' by researchers, 'including by establishing mechanisms for this purpose', and they must 'ensure [them] protection from retribution': ibid para 16(b)(ii). Such persons and institutions may depart from the rights of researchers in necessary cases, specified 'as explicitly and narrowly as possible': ibid para 16(b)(v).

${ }^{233}$ See specifically subs 5.4 below in this regard.

${ }^{234}$ UNESCO Recommendation 2017 (n 13) para 11 ('the principle of freedom of movement').

235 ibid para 42 (freedom of association is 'desirable').

${ }^{236}$ UNESCO Recommendation 1997 (n 44) para 26.

${ }^{237}$ ibid para 27 (definition of academic freedom).
} 
academic freedom play a secondary role in its overall scheme. The Preamble prominently points out that science 'open[s] up vast prospects for progress', but also 'entail[s] certain dangers'. ${ }^{238}$ This connects with the crux of the Recommendation, the state designing science policy so as to serve progress, while at the same time making sure 'humankind's vital interests', human rights, fundamental freedoms and the dignity of the human person are safeguarded. ${ }^{239}$ Only secondarily then - clearly making this nuance visible - '[it is] also recognis[ed]' that academic freedom should be protected. ${ }^{240} \mathrm{~A}$ further example of the secondary role accorded scientific and academic freedom can be found in paragraph 14(d), which mentions six goals of science education, such as the scientific method, intellectual integrity, skill in isolating ethical implications, and so on. ${ }^{241}$ Awareness of scientific and academic freedoms is conspicuously absent from the list. Is this secondary role perhaps the consequence of the fact that deeply distrustful policy makers have come to misconstrue freedom as 'irresponsibility'? ${ }^{242}$ All taken together, appreciating - as has been shown in Section 4 above - that scientific or academic freedom is the best guarantor of scientific progress in the interest of society at large, this should at least have ranked on a par with the state's role in regulating science and devising policies geared towards accelerating scientific progress for the benefit of society.

\subsection{An Instrumental Conception of Science and the Impact Agenda}

Overall, the Recommendation reflects a rather instrumental conception of science. States are required to ensure that science 'tackl[es] various world problems', 'strengthen[s] co-operation among nations', 'promot[es] the development of individual nations', ${ }^{243}$ helps 'set[ting] up a society that will be more humane, just and inclusive', 'enhance[s] ... the cultural and material wellbeing of its citizens', 'further[s] the United Nations ideals', ${ }^{244}$ and promotes 'the achievement of national goals'. ${ }^{245}$ 'Research and development is not [to be] carried out in isolation'. ${ }^{246}$ Does this leave room for science in the pursuit of knowledge for its own sake ${ }^{247}$ What about curiositydriven, blue skies research? What are national goals? Does development mean pure economic growth? Do the above goals countenance a mere impact agenda in science, valuing research essentially for its contribution to the knowledge economy?

\footnotetext{
${ }^{238}$ UNESCO Recommendation 2017 (n 13) Preamble, 1st (a).

${ }^{239}$ ibid Preamble, 1st (a), 1st (b).

240 ibid Preamble, 2nd (c).

241 ibid para $14(d)$.

${ }^{242}$ See Uwe Schimank, "New Public Management" and the Academic Profession: Reflections on the German Situation' (2005) 43 Minerva 361, 372 (noting that 'new public management' in universities construes freedom as 'irresponsibility').

${ }^{243}$ UNESCO Recommendation 2017 (n 13) Preamble.

244 ibid para 4.

245 ibid para 16(a)(iv).

246 ibid para 4.

${ }^{247}$ See, for example, Thaddeus Metz, 'A Dilemma Regarding Academic Freedom and Public Accountability in Higher Education' (2010) 44 Journal of Philosophy of Education 529 (emphasising the importance of academic freedom, guided by a sense of public morality, in the pursuit of knowledge, including knowledge for its own sake).
} 
The reality is that the notion of 'impact' has become all-pervasive in science, also in universities. John Ziman accordingly finds that we are in the age of 'post-academic science', where instrumental has displaced disinterested science. ${ }^{248}$ He holds that the ethos of trust sustaining disinterested science 'is being fatally undermined by [its] enforced cohabitation with instrumental research'. ${ }^{249}$ Philip Moriarty considers the impact agenda to systematically erode the Mertonian norms in academia, ${ }^{250}$ this driving publicly funded university research closer and closer to the PLACE norms of industrial science. ${ }^{251}$ He says that 'what is perhaps most dispiriting about the impact agenda is the extent to which the research councils and, most worryingly of all, universities themselves have abandoned any commitment to truly disinterested, curiosity-driven research'.252

Moreover, what about science as an aspect of the right 'to take part in cultural life', as protected in Article 15(1)(a) of the ICESCR? Lea Shaver emphasises that the value of science is not purely instrumental, but that there is also a value inherent in the process itself. Engaging in scientific discovery 'helps us to realise and express parts of our shared humanity, which has value from the perspective of individual development and the shared life of the community'. ${ }^{253}$ To be sure, paragraph 4 of the Recommendation, at its very end, benevolently adds that 'sufficient place [should be given] to science per se', but in the overall scheme of the Recommendation the message of this coda very much vanishes into thin air.

\subsection{Peer Review, Ethics and Intellectual Property Rights}

The Recommendation does not resolve - it even exacerbates - conflicts between scientific or academic freedom and other rights, interests and values worthy, or potentially worthy, of protection. It does not, for example, address conflicts between scientific or academic freedom and anti-terror legislation, the protection of confidential personal data, or employers' claims to honour and reputation. Three instances of conflict not resolved will be referred to here, namely:

- conflicts between scientific or academic freedom and peer review;

- conflicts between scientific or academic freedom and ethical regulation; and

- conflicts between scientific or academic freedom and intellectual property rights.

The Recommendation even intensifies conflicts in the cases of peer review and ethics.

\footnotetext{
${ }^{248}$ Ziman (n 103) 67-68.

${ }^{249}$ John Ziman, 'The Continuing Need for Disinterested Research' (2002) 8 Science and Engineering Ethics 397, 399. Not denying a role for agenda science as well, Arne Jarrick accordingly underlines that 'the scientific mission can only be properly executed if society provides ... researchers with an arena for basic research, protected from meddlesome interferences by too shortsightedly, too medially alarmist, and too ideologically or politically motivated encroachments': Jarrick (n 173) 63.

${ }^{250}$ Moriarty (n 170) 65.

251 ibid 69.

252 ibid 72.

${ }^{253}$ Lea Shaver, 'The Right to Science: Ensuring that Everyone Benefits from Scientific and Technological Progress' (2015) European Journal of Human Rights 411, 416.
} 
A new feature of the Recommendation not encountered in the 1974 version is the central role accorded to peer review. It is considered crucial to validate research findings. ${ }^{254}$ The Recommendation further expressly applies with respect to 'institutions and individuals responsible for ... peer review'. ${ }^{255}$ States are to 'establish [peer review] as a norm for any scientific publishing'. ${ }^{256}$ Finally, peer review is to form one component of performance appraisal for state employees. $^{257}$

It should, first of all, be pointed out that in the light of the high level of restraint required on the part of the state when it comes to organising science and scholarship referred to in Section 3, prescribing peer review as a requirement for scientific publishing, or for performance appraisals of at any rate academic staff in universities, lies beyond state powers. The forms of quality control that are necessary in a specific type of situation is a matter for the scientific fraternity to decide. Legislation can only (but must) oblige the scientific fraternity to give consideration to the issue. $^{258}$ The relevant provisions of the Recommendation must to that extent be regarded as unacceptable, therefore.

Peer review does have its place in science, but the sacrosanct status it is accorded in the Recommendation is not justified. With regard to the field of publishing, for example, it is generally not contested that peer review penalises innovation and non-conformity. ${ }^{259}$ Imad Moosa identifies a whole list of problems associated with peer review. Notably, for a well-written paper the submission outcome is governed by a stochastic process: 'Some academics would tell you that they had a paper rejected five times, only to be accepted for publication in a better journal at the end'. ${ }^{260}$ Larry Wasserman says peer review creates 'an illusion ... [of] ... quality control'. ${ }^{261}$ There are alternatives to current peer review. ${ }^{262}$ There is something to be said for oldfashioned editor review, for instance, which has proved to be fairly reliable. ${ }^{263}$ There should also

\footnotetext{
${ }^{254}$ UNESCO Recommendation 2017 (n 13) para 1(a)(1).

255 ibid para 2(c).

256 ibid para 26.

${ }^{257}$ ibid para 34(c). See also subs 5.6 below in this regard.

${ }^{258}$ Peer review and related quality controls cannot exist in an undemocratic legal vacuum in which they can escape judicial oversight. As elucidated in subs 3.3 above, in the state based on the rule of law, formal law must provide a basis for state competences (see n 157), including that of quality control in science. It has, however, also been stated that the detailed rules of the science system will have to be elaborated by the scientific fraternity, to which the state entrusts that task. The scientific fraternity will have to decide on the exact type or nature of quality controls considered 'adequate for science'.

${ }^{259}$ Mary Biggs, 'The Impact of Peer Review on Intellectual Freedom' (1990) 39 Library Trends 145, 162. The peer review process is inherently conservative. The more established reviewers are as researchers, having attained a certain professional 'comfort zone', the more likely they will be to prevent unconventional ideas from being published. In this sense, see ibid 159-62. Moreover, peer review rewards following trends rather than achieving long-term value: see Kent (n 199).

${ }^{260}$ Moosa (n 201) 120. Problems of peer review which Moosa thus mentions are, inter alia, its random nature, its bias against new ideas, referees' obsession with finding faults, delays in publishing, referee incompetence, or referee dishonesty: ibid Ch 7.2-7.10.

${ }^{261}$ Larry Wasserman, 'A World Without Referees' (2012) 19(1) ISBA Bulletin 7, 7.

${ }^{262}$ See Moosa (n 201) 135-37 (discussing alternatives to peer review).

${ }^{263}$ To the extent that this relies on referees see, for example, Bruno S Frey, 'Publishing as Prostitution? Choosing between One's Own Ideas and Academic Success' (2003) 116 Public Choice 205, 218 (arguing that the editor should make a decision on publication, while the referees should only offer suggestions for improvement).
} 
be forms of collaborative verification by the larger scientific community, for example, through open access archive systems. ${ }^{264}$ Another option is to dispense totally with the need for a (structured) review process: 'Good ideas will get recognised, used and cited. Bad ideas will be ignored' ${ }^{265}$ In any event, courts must be granted powers of review to adjudge compliance of peer review (or other forms of quality control) with scientific and academic freedom - also when such review or control is performed by, or on behalf of, commercial or other scientific publishers. ${ }^{266}$

Another new feature of the Recommendation is the requirement that states should 'establish ... suitable means to address the ethics of science ... specifically through establishing, promoting and supporting independent, multidisciplinary and pluralist ethics committees'. These are to provide ethical advice and assess scientific developments. In particular, they are 'to assess the relevant ethical, legal, scientific and social issues related to research projects involving human beings' ${ }^{267}$ Due account is to be taken of ethics compliance in performance appraisals. ${ }^{268}$ There are many other references to ethics. ${ }^{269}$ The 1974 version of the Recommendation contained only three brief references to ethics. The importance of ethics assessments is undisputed in many cases, notably in the context of medical research. What is important to remember, however, is that every ethics assessment in principle impacts on scientific or academic freedom and, therefore, requires justification. The Recommendation does stipulate that employers should install ethics review boards. ${ }^{270}$ Beyond that, however, the essential conflict between ethics and scientific or academic freedom is left unaddressed.

Ethics assessments are perhaps not a suitable instrument in the humanities and social sciences (HSS). The extra work and the delays they entail may disproportionately discourage research in these fields. ${ }^{271}$ It has been argued that ethical regulation in HSS '[causes] damage to wider interests in acquiring reliable and valid information about the social, political, economic and cultural life of our society'. ${ }^{272}$ Moreover, ethics assessment may easily assume the form of a broad moral review. ${ }^{273}$ The great achievement of modern science lies exactly in the fact that it has been able to accomplish a demoralisation. Attempts of a remoralisation should be resisted. ${ }^{274}$ Where does one draw the line between ethical regulation and censorship? What has become of scientific or

\footnotetext{
${ }^{264}$ See Kent (n 199) (proposing this model).

${ }^{265}$ Wasserman (n 261) 7.

${ }^{266}$ See also $\mathrm{n} 77$ (enforcement against scientific publishers).

${ }^{267}$ UNESCO Recommendation 2017 (n 13) para 5(d) (emphasis added).

268 ibid para 34(a).

269 See ibid Preamble, paras 12, 14(c), (d)(ii), (iv), 16(a)(iii), (vi), (b)(ii), 18(b), 20(a).

270 ibid para 16 (b)(ii).

271 Barendt (n 43) 208-09.

${ }^{272}$ Robert Dingwall, 'The Ethical Case against Ethical Regulation in Humanities and Social Science Research' (2008) 321 st Century Society 1, 7.

${ }^{273}$ Inter alia, for this reason - that is, ethical indeterminacy - ethical regulation must be subjected to strict judicial control: see Ralf Poscher, 'Was Juristen besser können als Ethiker: Ein interdisziplinäres Argument für die gerichtliche Kontrolle von Ethikkommissionen' in Silja Vöneky and others (eds), Ethics and Law: The Ethicalization of Law (Springer 2013) 433, 436-41 (in German).

${ }^{274}$ In this sense, see also Schulte (n 158) 138-39.
} 
academic self-duty? ${ }^{275}$ Yet again, the state's duty of restraint in organising science and scholarship should be kept in mind. This is especially so when it comes to regulating instances beyond the clearer cases in which ethics assessment may or should be deemed compulsory, or where the specificities relating to the establishment of ethics codes and bodies in universities and research institutions, and beyond, are concerned. Again, courts must be granted powers of review to ensure that ethical regulation duly respects scientific and academic freedom, does not disproportionately undermine scientific progress, is guided by principles of a rational responsibility not to cause harm, and, when inspired by human dignity, only protects human dignity as a human rights (and not a moral) concept. Altogether, therefore, ethical regulation needs to steer much more of a middle course.

The Recommendation does not address conflicts between scientific or academic freedom and intellectual property rights in any more detail. The novelty requirement of patent law delays the publication of research results. ${ }^{276}$ The copyright of scientific publishers obstructs access to scientific knowledge. ${ }^{277}$ The Recommendation does call for 'balancing between protection of intellectual property rights and the open access and sharing of knowledge'. ${ }^{278}$ It should, however, also have included specific suggestions for statutory limitations and exceptions to copyright protection that states could implement to safeguard access to scientific knowledge in educational or scientific institutions, libraries and archives. ${ }^{279}$ Insofar as the intellectual property rights of scientists themselves are concerned, the Recommendation does little to add to or strengthen these. It vaguely calls for 'appropriate' legal protection of intellectual property rights, provides that employers should respect (those) intellectual property rights (that scientists may be granted), and insists that intellectual property rights be 'stated clearly' in employment contracts (not saying, however, what must be included or may not be excluded). ${ }^{280}$ Restrictions on the right to publish should be 'strictly minimised'. ${ }^{281}$ Does this also apply to restrictions imposed on university researchers by government or industry commissioning research? The Recommendation

\footnotetext{
${ }^{275}$ The literature mentions many other problems associated with ethical regulation: see, for example, Rebecca Boden, Debbie Epstein and Joanna Latimer, 'Accounting for Ethos or Programmes for Conduct? The Brave New World of Research Ethics Committees' (2009) 57 Sociological Review 727, 745-46 (arguing that, rather than regulating research ethics, the apparatus for its regulation is used 'to elicit conformity through a disciplinary effect[,] ... [this being] wholly destructive to critical social science'); Adam Hedgecoe, 'Reputational Risk, Academic Freedom and Research Ethics Review' (2016) 50 Sociology 486, 495 (explaining that ethics committees are often being used to deter threats to an institution's reputation, academic freedom being undermined in this way).

${ }^{276}$ For an analysis of this conflict, see Joseph Straus, 'Intellectual Property versus Academic Freedom? A Complex Relationship within the Innovation Ecosystem' in Lars Engwall and Denis Weaire (eds), The University in the Market (Portland Press 2008) 53, 57-65.

${ }^{277}$ For a description of how modern copyright law - including, in the digital age, through its protection of electronic databases - restricts access to scientific knowledge, see Sara Bannerman, International Copyright and Access to Knowledge (Cambridge University Press 2016) 32-52.

${ }^{278}$ UNESCO Recommendation 2017 (n 13) para 18(d). See also ibid para 36 (member states to encourage access to knowledge and open access).

${ }^{279}$ Ultimately, even the World Intellectual Property Organization (WIPO) is now addressing this topic: see Bannerman (n 277) 50 (referring to developments at WIPO in this regard).

${ }^{280}$ UNESCO Recommendation 2017 (n 13) paras 37, 16(b)(iii), 40, respectively.

${ }^{281}$ ibid para $38(a)$.
} 
ultimately mentions restrictions within the ambit of employment contracts only, but does not refer to contracts of independent contractors. ${ }^{282}$ In times where outside actors increasingly hold proprietary interests in the research findings of universities, the Recommendation should have offered clearer rights to university researchers in this context.

\subsection{The Vigorous Entrepreneurialisation of Universities and Neoliberalism}

It is now commonly stated that the university of the future is entrepreneurial in nature. The case for the entrepreneurial university has notably been made by Henry Etzkowitz. ${ }^{283}$ Alongside teaching and research, the entrepreneurial university, according to Etzkowitz, has a third mission: the 'capitalization of knowledge'. ${ }^{284}$ Close links between university, industry and government are 'the key to innovation and growth in a knowledge-based economy' ${ }^{285}$ For Etzkowitz, the entrepreneurial university is 'an economic actor in its own right'. ${ }^{286}$ Its endeavours are essentially directed at developing intellectual property through research and then organising the transfer of technology to the economy through patenting, licensing and incubation (creating spin-off firms). ${ }^{287}$ For this new type of university to fulfil its mission successfully, there must exist 'an entrepreneurial ethos among administrators, faculty, and students'. ${ }^{288}$

Also Burton Clark has argued in favour of the entrepreneurial university. ${ }^{289}$ Besides its traditional faculties and departments, the entrepreneurial university crucially requires an 'expanded developmental periphery', comprising interdisciplinary project-oriented research centres and further 'professionalised outreach offices that work on knowledge transfer, industrial contact, intellectual property development, continuing education, [and] fundraising'. ${ }^{290}$ Universities need to develop a 'diversified funding base'. ${ }^{291}$ Major components of such a funding base are increased study fees and 'third-stream income sources that stretch from industrial firms, local governments, and philanthropic foundations, to royalty income from intellectual property, earned income from campus services, ... and alumni fundraising'. ${ }^{292}$ Clark similarly emphasises the need to create an 'integrated entrepreneurial culture' as an element in the process of transformation in universities. ${ }^{293}$

\footnotetext{
282 ibid (restrictions to be 'properly communicated ... in the terms and conditions of ... employment'). See also ibid para 40(a) ('written provisions [on rights of exploitation] to be included in the terms and conditions of employment').

${ }^{283}$ Henry Etzkowitz, The Triple Helix: University - Industry - Government, Innovation in Action (Routledge 2008).

284 ibid 27.

285 ibid 1.

286 ibid 27.

287 ibid.

288 ibid.

${ }^{289}$ Burton R Clark, Creating Entrepreneurial Universities: Organizational Pathways of Transformation (Emerald 1998).

290 ibid 6.

291 ibid 6-7.

292 ibid 6.

293 ibid $7-8$.
} 
Does the emergence of the entrepreneurial university constitute a threat to universities and university research? Ben Martin answers this question in the negative. ${ }^{294} \mathrm{He}$ argues that the 'classical' university should not be seen as the perfect and final embodiment of the idea of the university. The university is 'a very adaptable organism', he says. ${ }^{295}$ Martin examines the role of the mediaeval university, universities and science academies of the Age of Enlightenment, the Humboldtian university, universities focusing on applied research, and teaching-intensive higher education institutions, ${ }^{296}$ and concludes that the modern university with a third mission is not new. ${ }^{297}$ He holds that this university represents a stage in an evolutionary process in which universities have always been (and will always be) either more or less instrumentally oriented, depending on the exact economic, social and political environment prevailing at the relevant time. ${ }^{298}$

Martin's perspective is certainly interesting, but probably too naive. In this author's view, the entrepreneurial university of our time is not something that has been there previously, just in another guise. We are not merely, as a result of pressing needs of society, witnessing a reversion to more utilitarian conceptions of the university as they prevailed, for instance, during the Middle Ages or the Age of Enlightenment, or as manifest thereafter in the form of, for example, technical universities. What we are witnessing is rather a paradigm shift, entailing the wholesale abandonment of a thousand-year-old understanding of the university. For even if universities previously also served utilitarian goals, they always served the public good, facilitated comprehensive critical enquiry, and clearly related knowledge to the human being. The modern university, however, solely serves economic growth as an end in itself. Never before have universities forfeited criticality as absolutely as they do today. Ronald Barnett says that in today's university the 'critical component is arrested at the instrumental level'. ${ }^{299}$ Newer forms of study accept the world largely as given and merely seek to produce more effective operations within it. ${ }^{300}$ Even the mediaeval university, with its strong emphasis on teaching practical skills, was not instrumental in this sense as the mediaeval curriculum was still premised on the notion that comprehension of the outer (technical) world had to be embedded in reflection on the person's inner world. ${ }^{301}$ Critical thinking is being displaced "in the wake of the emergence of "the entrepreneurial university" and the development of market principles in higher education'. ${ }^{302}$ Hence, what we are witnessing today is certainly new. There is a complete break with the idea of the university as it has existed hitherto.

\footnotetext{
${ }^{294}$ Ben R Martin, ‘Are Universities and University Research under Threat? Towards an Evolutionary Model of University Speciation' (2012) 36 Cambridge Journal of Economics 543.

295 ibid 559.

296 ibid $545-47$.

297 ibid 548-49, 551-53, 555-56, 558-59. At 549, Martin says, "[t]he "third mission" was present from the earliest years of the university'.

298 ibid 558-60.

${ }^{299}$ Ronald Barnett, Higher Education: A Critical Business (Society for Research into Higher Education and Open University Press 1997) 79.

300 ibid.

301 ibid.

302 Thus, Martin Davies and Ronald Barnett, 'Introduction' in Martin Davies and Ronald Barnett (eds), The Palgrave Handbook of Critical Thinking in Higher Education (Palgrave Macmillan 2015) 1, 1-2.
} 
In the words of Basil Bernstein, '[k]nowledge, after nearly a thousand years, is divorced from inwardness and is literally dehumanized'. ${ }^{303}$

It is often said that the entrepreneurial university is a response to the exigencies of our times. ${ }^{304}$ With the end of the Cold War, globalisation, the worldwide opening of markets and increasing competition, it is claimed that national economies will be able to survive only if there is an enhanced emphasis on, and if governments pursue explicit policies towards, science, innovation and technology. ${ }^{305}$ Simultaneously, student enrolments are to be increased substantially to meet the ever-growing needs of the knowledge economy. ${ }^{306}$ Limited public resources, it is said, imply 'increasing demands for accountability, effectiveness, relevance and value for money' with regard to research and teaching. ${ }^{307}$ All this is to delude us into believing that the entrepreneurial university, in the current economic, social and political context, is a necessary solution, following logically, as it were, from the applicability of some law of nature, rather than the product of choice based on ideology. One should agree with Ourania Filippakou and Gareth Williams in their holding that the entrepreneurial university is not so much the consequence of the expansion of higher education, but is 'primarily the result of ideological changes which have led to the current global dominance of neoliberalism'. ${ }^{308}$

Neoliberalism rejects the idea of the public good paid for by the state. It believes in private investment, that is, investment in the self. This, as Pierre Bourdieu points out, is really an extension of the Calvinist tenet that 'God helps those who help themselves'. ${ }^{309}$ Under neoliberalism, the individual, '[w] hether he is selling, making, or consuming ... is investing in himself and producing his own satisfaction'. ${ }^{310}$ The individual who is political (homo politicus) and possessed of inherent dignity (homo humanum) is displaced by the homo oeconomicus, the economic person. Interestingly, as Michel Foucault explains, the homo oeconomicus of neoliberalism (unlike his classical counterpart) is surprisingly unfree and eminently governable. ${ }^{311}$ This individual does not live freedom but is to be morally 'responsibilicised' through economics. ${ }^{312}$ Also this is an extension of Calvinist notions of governing the subject through reward and punishment. Relying on these instruments, the state ceases to be a provider of welfare and governs from a

\footnotetext{
${ }^{303}$ Basil Bernstein, Class, Codes and Control: The Structuring of Pedagogic Discourse (Class, Codes and Control, Vol IV, Routledge 2003) 134.

${ }^{304}$ See Martin (n 294) 554-55 ('global driving forces for change').

305 ibid 554 .

306 ibid 555 .

307 ibid 554 .

${ }^{308}$ Ourania Filippakou and Gareth Williams, 'Academic Capitalism and Entrepreneurial Universities as a New Paradigm of "Development"” (2014) 1 Open Review of Educational Research 70, 81.

${ }^{309}$ Pierre Bourdieu, The Social Structures of the Economy (Chris Turner tr, Polity Press 2005) 11.

${ }^{310}$ Wendy Brown, Undoing the Demos: Neoliberalism's Stealth Revolution (Zone Books 2015) 80.

${ }^{311}$ Michel Foucault, The Birth of Biopolitics: Lectures at the Collège de France, 1978-79 (Graham Burchell tr, Michel Senellart ed, Palgrave Macmillan 2008) 270.

${ }^{312}$ Michael A Peters, 'Education, Neoliberalism, and Human Capital: Homo Economicus as "Entrepreneur of Himself"' in Simon Springer, Kean Birch and Julie MacLeavy (eds), The Handbook of Neoliberalism (Routledge 2016) 297, 301.
} 
distance. The sole purpose of the neoliberal project, as Wendy Brown stresses, is 'macroeconomic growth and credit enhancement'. ${ }^{313}$

In this sense, then, higher education and science are increasingly ceasing to be public goods. Higher education and science are deliberately being underfunded. A range of 'instruments of responsibilisation' - incentives, hierarchies, standards, measures and audits - seek to induce universities, and the scientists they engage, to produce science for the economy. In the process, universities lose their independence and scholars their freedom of enquiry. ${ }^{314}$ The entrepreneurial university encompasses ideas of performance, accountability and capitalisation of self. ${ }^{315}$ While this type of university may legitimately play a supplementary role, it should not be the leitmotif for university development. Where homo oeconomicus becomes the measure for university development, this undermines human dignity as the foundational value of the REBSPA in Article 15(1)(b) of the ICESCR. ${ }^{316}$

The UNESCO Recommendation should have contrived an effective response to the dwindling independence of universities and the erosion of individual academic freedom in universities that have occurred since the mid-1980s, precipitated by the implementation of neoliberal higher education and science policies. Mathias Binswanger thus laments that the modern university is only marginally concerned with gaining knowledge. He says that today's universities are 'fundraising institutions' and 'publication factories', managed by principals who are 'sort of a CEO'. ${ }^{317}$ Neoliberal policies - in the concrete form of what has been called corporatism above - have had a devastating effect on science in universities and research institutions. ${ }^{318}$ The Recommendation does not deal with the corporate threat to science at all. This is quite remarkable when one considers that the literature describes the current situation as one close to a 'breakdown of scientific thought'. 319

\footnotetext{
313 Brown (n 310) 84.

${ }^{314}$ In a similar vein, Schimank (n 242) 366 ('In this game, the academic profession is the loser. External interests, university leaders, and especially Government seem to be the winners').

${ }^{315}$ Filippakou and Williams (n 308) 75-76.

${ }^{316}$ See subs 2.5 above (REBSPA, human rights quality, human dignity).

${ }^{317}$ Binswanger (n 171) 53.

${ }^{318}$ In this context, refer to the discussion in Section 4 above.

${ }^{319}$ See Hasselberg, Rider and Waluszewski (n 11). Some of the literature that has been published on the topic of neoliberalism in, and the corporatisation of, higher education and science includes Angathevar Baskaran and Rebecca Boden, 'Commodified Science and Social Wellbeing' (2007) 21 AI \& Society 267; Derek Bok, Universities in the Marketplace: The Commercialization of Higher Education (Princeton University Press 2003); Frank Donoghue, The Last Professors: The Twilight of the Humanities in the Corporate University (Fordham University Press 2008); Giroux (n 10); Daniel S Greenberg, Science for Sale: The Perils, Rewards, and Delusions of Campus Capitalism (University of Chicago Press 2007); Carl Rhodes, 'Academic Freedom in the Corporate University: Squandering Our Inheritance?' in Izak, Kostera and Zawadzki (n 189) 19; Ellen Schrecker, The Lost Soul of Higher Education: Corporatization, the Assault on Academic Freedom and the End of the American University (New Press 2010); Sheila Slaughter and Larry L Leslie, Academic Capitalism: Politics, Policies, and the Entrepreneurial University (Johns Hopkins University Press 1997); Henry Steck, 'Corporatization of the University: Seeking Conceptual Clarity' (2003) 585 The Annals of the American Academy of Political and Social Science 66; James L Turk, 'Anatomy of a Corporate Takeover', The UNESCO Courier, November 2001, 18; Jennifer Washburn, University Inc.: The Corporate Corruption of Higher Education (Basic Books 2005); Rob Watts, Public Universities, Managerialism and the Value of Higher Education (Palgrave Macmillan 2017); Howard R Woodhouse, Selling Out: Academic Freedom and the
} 


\subsection{Accountability Excess and Staff Performance Appraisals}

There is an obsession these days with accountability in higher education and science. Accountability appears to supersede rights. Even the Recommendation, before stating that scientific researchers are entitled to 'freedom of research', posits that 'scientific researchers [must] respect public accountability'. ${ }^{320}$ The Recommendation leaves open what 'public accountability' means. In so doing, it opens the door to states giving this a neoliberal interpretation. Accountability would then mean using taxpayers' money only towards 'useful' science and producing sufficient quantifiable output. Performance is to be assessed. On closer scrutiny, public accountability has become more of a bogus concept, easily applied to restrict freedoms and exercise control. In higher education and science, its use is more hypocritical than sincere. ${ }^{321}$

It has already been pointed out above how resource-intensive - wasteful on taxpayers' money 'accountability', as currently understood, really is. ${ }^{322}$ To mention another example, the demand for academics performing peer review at the request of large publishing houses has increased exponentially. While the latter save on money for quality control, this is performed by academics (ultimately) paid by the state. The state accordingly subsidises private companies. ${ }^{323}$ Subsequently, the state (or its money) purchases, or acquires licences in respect of, the same journals and books, the production of which it has subsidised, at excessive prices to resource research libraries, thus paying public money to the private sector for a second time. ${ }^{324}$ By way of a third and final example, trying to meet performance measures of accountability involves a change of research strategy by scientists and their institutions - namely, the avoidance of risk in science to ensure that results and 'output'

Corporate Market (McGill-Queen's University Press 2009). Underlining the aspect of higher education and science as a 'public good' in this respect, see Peder Andersen, 'Research, Global Public Goods and Welfare' in Erik A Andersen and Birgit Lindsnaes (eds), Towards New Global Strategies: Public Goods and Human Rights (Martinus Nijhoff 2007) 335; Morten Levin and Davydd Greenwood, Creating a New Public University and Reviving Democracy: Action Research in Higher Education (Berghahn Books 2017); Moriarty (n 170) 65; Richard R Nelson, 'The Market Economy, and the Scientific Commons' (2004) 33 Research Policy 455; Christopher Newfield, The Great Mistake: How We Wrecked Public Universities and How We Can Fix Them (Johns Hopkins University Press 2018); Helga Nowotny and others, The Public Nature of Science under Assault: Politics, Markets, Science and the Law (Springer 2005).

${ }^{320}$ UNESCO Recommendation 2017 (n 13) para 10.

${ }^{321}$ As has been well explained, 'accountability' in the modern university is applied in a perverted sense to mean discipline, surveillance and value for money. Its use amounts to a 'sinister assault on academic freedom': Rafael Winkler, 'Universities in the Neoliberal Age', Mail \& Guardian, 14 September 2018, https://mg.co.za/article/ 2018-09-14-00-universities-in-the-neoliberal-age.

322 See subs 4.2 above (the argument under 'firstly').

${ }^{323}$ In this sense, Susan Wright, 'Measurements and Distortions: A Review of the British System of Research Assessment', Working Papers on University Reform, Working Paper 9, June 2008, 19, 21-23. Alternatively, it can be argued that academics work for free for expensive journals: in this sense, Theodore C Bergstrom, 'Free Labor for Costly Journals?' (2001) 15(3) Journal of Economic Perspectives 183.

${ }^{324}$ A look at the websites of the big publishing companies reveals that at any rate a perceived 50 per cent of all scholarly journal articles and books ever published date from the last five to ten years. Has knowledge really increased so much during this period? The public cost implications are immense. For an account of scholarly publishing as the 'multi-billion-dollar industry', see Heather Morrison, Scholarly Communication for Librarians (Chandos Publishing 2009) 35-56. 
can be delivered. ${ }^{325}$ However, with risk being a sine qua non for scientific progress, financing a science system destined not to yield scientific progress epitomises a waste of public resources. In many ways, the current accountability excess inhibits scientific progress.

As Stefan Collini points out, the public, supposedly claiming that state resources should not be squandered, in reality is bothered less about taxpayers' money and accountability. It does not want to hear how much scholarship and science will contribute to the GNP. It wants to know that, 'somewhere, human understanding is being pressed to its limits, unconstrained by immediate practical outcomes'. ${ }^{326}$ He holds that, in fact, universities are now less efficient than they were twenty years ago. This is so, he argues, because a bureaucratic system of constant measurement leaves little room for two of the most important sources of efficiency in intellectual activity: voluntary co-operation and individual autonomy. ${ }^{327}$

This then links up with another issue to be discussed here: staff performance appraisals. Whereas the 1974 version of the Recommendation considered 'appraisals' more of a conceivable instrument, ${ }^{328}$ the 2017 Recommendation makes them mandatory for state employees: 'States should ... design ... appraisal systems'. ${ }^{329}$ The 1997 UNESCO Recommendation concerning the Status of Higher-Education Teaching Personnel considers the 'major function [of appraisal] [to be] the development of individuals in accordance with their interests and capacities'. ${ }^{330}$ The 2017 Recommendation does not mention this consideration at all. Both the 1974 and the 1997 Recommendations emphasised that appraisal would have to 'take due account ... of the difficulty inherent in measuring [a] personal capacity'. ${ }^{331}$ The 2017 Recommendation mentions this consideration in a rather subsidiary fashion. ${ }^{332}$ The emphasis is now on 'all aspects of the work including, inter alia, contributions to publications, patents, management, teaching, outreach, supervision, collaboration, ethics compliance, and science communications'. ${ }^{333}$ The test, as formulated, has a quantitative tick-box appeal, completely absent in the tests of both the 1974 and the 1997 Recommendations. As seems to happen in many countries, contributions are frequently simply quantified (number of publications, patents, and so on). The 2017 Recommendation states that '[a]ppropriate metrics [should be combined] with independent expert assessment (peer review)'. ${ }^{334}$ Paternalistically, peer review is to be a magic cure to be prescribed by the state ${ }^{335}$-and, recourse is

\footnotetext{
${ }^{325}$ In this sense, see Lawrence (n 10) R584.

${ }^{326}$ Collini (n 181) Ch 5.1.

${ }^{327}$ ibid Ch 7.1. Collini goes on to state: 'We all certainly report on ourselves much more fully than we did twenty or thirty years ago, but the unintended by-product of that may be that we concentrate our energies a bit more on doing things that are reportable. It is a mistake to think that if you make people more accountable for what they do, you will necessarily be making them more efficient at doing it': ibid.

${ }^{328}$ UNESCO Recommendation 1974 (n 215) para 32.

${ }^{329}$ UNESCO Recommendation 2017 (n 13) para 34.

${ }^{330}$ UNESCO Recommendation 1997 ( $\mathrm{n} 44$ ) para 47(a). This consideration also underlies the appraisal provision of the 1974 UNESCO Recommendation (n 215) para 32(b).

${ }^{331}$ UNESCO Recommendation 1974 (n 215) para 32(a); UNESCO Recommendation 1997 (n 44) para 47(c).

332 UNESCO Recommendation 2017 (n 13) para 34(b).

333 ibid para 34(a).

334 ibid para 34(c).

${ }^{335} \mathrm{See}$ also the discussion of peer review in subs 5.4 above in this regard.
} 
to be had to metrics! Does the Recommendation honestly propose the use of metrics (that is, quantitative targets) in staff appraisals? This is corporatism at its worst. Metrics will often mismeasure because ' $[n]$ ot everything that counts can be counted'. ${ }^{336}$ Metrics incentivise scholarly dishonesty, are inherently autocratic and based on distrust, and often have unintended, counterproductive consequences ( such as the avoidance of risk in science). ${ }^{337}$

Performance appraisals are part of a system that seeks to enhance scholarly output through rewards - financial or moral (researchers can become 'rock star' academic researchers) ${ }^{338}$ and punishment (refusal of funding, non-promotion, dismissal). However, as Collini points out, good scholarly work is not a quantitative goal - it cannot be measured by university administrators, but needs to be judged by the larger scientific community in the long term. ${ }^{339}$ Moreover, no measure of appraisal can compel the production of the thing that matters most - intellectual quality in research. ${ }^{340}$ This either exists, or it never will.

\subsection{Inclusive Governance, Collegiality and Participation}

Finally, in universities the protection of individual academic freedom presupposes the existence of arrangements to ensure that decisions on science that are collective in nature will be 'adequate for science'. ${ }^{341}$ In effect, this lies at the basis of the requirements of self-governance and collegiality as provided for in the UNESCO Recommendation concerning the Status of Higher-Education Teaching Personnel of 1997. ${ }^{342}$ Apart from conferring on scientific researchers the right 'to contribute to the definition of the aims and objectives of [research] programmes ...

\footnotetext{
${ }^{336}$ Collini (n 181) Ch 6.1. How, for example, should scholarship, in the sense of staying up to date with one's subject by independent study, be measured? By the number of hours spent in the library?

${ }^{337}$ Critically commenting on the use of performance metrics, see, for example, Susanne Baer, 'Verantwortung für die Wissenschaftsfreiheit' (2015) 48 Wissenschaftsrecht 3, 6 (stating that 'the normative rationality of science' mandates that 'the use of metrics, the mere quantified processing of data and one of its driving forces, economisation, may not dominate') (in German); Edwards and Roy (n 10) 53 (holding that metrics create 'perverse incentives' as they pressurise scientists 'to overemphasize quantity at the expense of quality ... [and] to "cut corners"'); Liz Morrish and Helen Sauntson, 'Performance Management and the Stifling of Academic Freedom and Knowledge Production' (2016) 29 Journal of Historical Sociology 42 (arguing that academic freedom is detrimentally affected by a system of quantitative targets and constant surveillance). Generally and fundamentally, see Michael Power, The Audit Society: Rituals of Verification (Oxford University Press 1999) (manner of operation questionable, dysfunctionality, unintended consequences).

${ }^{338}$ On 'rock star' academic researchers, see Smyth (n 214) 99-123.

${ }^{339}$ Collini (n 181) Ch 7.2. Milton Friedman stated that 'the true test of a scholar's work is the judgment that is made not at the time his work is being done, but twenty-five or fifty years later': Milton Friedman and Rose D Friedman, Two Lucky People: Memoirs (University of Chicago Press 1999) 442.

${ }^{340}$ Collini (n 10) Ch 2.2 .

${ }^{341}$ On the term 'adequacy for science', see n 18 and accompanying text.

${ }^{342}$ On the importance of self-governance and collegiality in the university context, see Robert Birnbaum, 'The End of Shared Governance: Looking Ahead or Looking Back' (2004) 127 New Directions for Higher Education 5, 20 ('The basic question to ask is not whether we want to make governance more efficient, but whether we want to preserve truly academic institutions. If the answer is affirmative, then shared governance is an essential precondition'); Jan de Groof, Guy Neave and Juraj Švec, Democracy and Governance in Higher Education (Kluwer Law International 1998) 3 ('University government ought to reflect ... the democratic ethic'); Ginsberg (n 191) 218 ('[S]hort-term or part-time faculty administrators are to be preferred to professional administrators. Faculty administrators are usually committed to the primacy of the university's academic mission ... [and] have no particular
} 
and to the determination of the methods to be adopted', ${ }^{343}$ the 2017 Recommendation does not comment on issues of inclusive governance, collegiality and participation in institutions of science and their sub-units. While academic staff in universities will enjoy rights of self-governance and collegiality under the 1997 Recommendation (this constitutes lex specialis for university staff and will supersede the 2017 Recommendation whenever the standards of protection of the earlier Recommendation are higher), ${ }^{344}$ the 'adequacy for science' of decisions on science that are collective in nature should similarly be ensured beyond the university context, notably in public non-university research institutes. These institutes will usually be headed by a director and there would be governing bodies with government representatives among the members. Although the employees of these research institutes do not enjoy the same measure of scientific freedom as is enjoyed by university staff, rights of participation or self-regulation need some form of protection here, too. Senates and other bodies composed of scientific staff, representation in governing bodies, voting rights, and so on, will usually have to be provided for. ${ }^{345}$

\section{Recommendations for a Science System 'Adequate for Science': Scientific or Academic Freedom Remains the Best Guarantor of SCIENTIFIC Progress}

The REBSPA in Article 15(1)(b) of the ICESCR should not be interpreted as granting governments carte blanche to regulate science 'in the interest of society'. It does not accord legitimacy to utilitarian conceptions of science - worst in the form of corporatism - to advance a reductive, economistic form of progress in society. Scientific or academic freedom, by reason of its contribution to discovering the truth, remains the best guarantor of scientific progress in the interest of society at large.

\footnotetext{
interest in administrative aggrandizement'); Hochschulfusion [University Merger] case (n 133) para 68 ('Essentially scientific decisions are to be taken by organised science itself'); Cary Nelson, No University Is an Island: Saving Academic Freedom (New York University Press 2010) 31 ('[A]cademic freedom is really only one leg of a three-legged stool. Academic freedom, shared governance, and tenure together support the higher education system'); Michael Shattock, 'University Governance, Leadership and Management in a Decade of Diversification and Uncertainty' (2013) 67 Higher Education Quarterly 217, 232 (stressing the importance of a 'collegial, participative culture' in universities); Michael Shattock, Managing Good Governance in Higher Education (Open University Press 2006) 155 ('[T]he evidence suggests that universities are better run the more their staff are fully engaged with the pressures that confront them'); Bjørn Stensaker and Agnete Vabø, 'Re-inventing Shared Governance: Implications for Organisational Culture and Institutional Leadership' (2013) 67 Higher Education Quarterly 256, 271 (holding that entrepreneurial governance readily negatively affects important 'symbolic and cultural functions' of shared governance arrangements).

${ }^{343}$ UNESCO Recommendation 2017 (n 13) para 16(a)(ii). See also ibid paras 8, 16(a)(iv), referred to at $\mathrm{n} 230$.

${ }^{344}$ While the 2017 Recommendation (n 13) deals with scientists generally, the 1997 Recommendation (n 44) covers only a specific type of scientist - those who work in higher education. Hence, it formulates rights and duties specific to teachers and researchers in higher education. See also nn 66-72 and accompanying text in this regard. ${ }^{345}$ Admittedly, international and even national literature on the topic is scarce. A useful guide is the book by Thomas Groß and Natalie Arnold, Regelungsstrukturen der außeruniversitären Forschung: Organisation und Finanzierung der Forschungseinrichtungen in Deutschland (Nomos 2007) (in German) (containing a detailed examination of the legal organisation of non-university research institutes in Germany).
} 
The critique here has not been to say that science should not benefit society. Apart from it being important that science should be a rewarding experience for the scientist on a personal level, it should clearly also benefit society. The intention here has been to point out that there are limits to the ability and legitimacy of the state in securing benefits for society through regulation. Too many a priori decisions on what constitutes 'useful', 'good' science and what constitutes 'superfluous', ' $b a d$ ' science tend to yield no science, after all. It is not the prescriptive state, but scientific or academic freedom that best secures benefits for society. Excessive regulation stifles creativity and innovation. Like the weather, discovery is not manageable. It simply happens, provided an 'adequate' framework for science exists.

This article has raised four caveats to guide all those tasked with interpreting Article 15(1)(b). Underlying these four caveats, the concept of 'adequacy for science' has been proposed as an antidote to utilitarianism and corporatism in science. This should be the crucial test for the REBSPA. Hence, in order to properly implement the REBSPA - to properly realise the human dignity on which that right is founded - the focus, rather than on the individual, society or the economy, should be on science itself. What is good, or 'adequate', for science will also realise the human dignity of the REBSPA. Structures, arrangements and decisions in the field of science must, therefore, be such as will be 'in the best interest of science and scholarship'. There must be respect for the intrinsic requirements of science and the central role that scientists themselves should play in organising science. All this necessarily implies an effective protection of scientific and academic freedom.

The article has made some initial suggestions as to when a science system can be considered 'adequate for science' in the light of scientific and academic freedom. Future research needs to concretise these suggestions. The following 22 recommendations broadly encapsulate the suggestions made.

1. Descriptive regulation The science system must protect a space of absolute freedom as part of scientific and academic freedom. This space covers all activity related to gaining, interpreting and communicating scientific insights. This absolute freedom does not permit prescriptive, but only descriptive regulation - that is, regulation describing rights and duties naturally 'part and parcel' of scientific and academic freedom.

2. Prescriptive regulation Beyond this space of absolute freedom, scientific or academic freedom may be in tension with other 'supreme' values or others' human rights. In these cases, regulation that is necessary to protect human dignity, confidential personal data or certain intellectual property interests, or to advance the enjoyment of the benefits of scientific progress, and so on, may take on a more prescriptive character. Any such regulation must be aimed at achieving a balance of rights and duties that duly respects scientific and academic freedom. Regulation under the REBSPA that seeks to promote science for human benefit must proceed cautiously and requires careful 'reasonableness' justification, as such regulation, by its nature, tends to render inoperative the autonomous laws of science, the operation of which secures discovery. Especially all instances of 'planning 
science' in the university context intended to yield the delivery of external goods to the wider society are, in principle, suspect.

3. Limitation Scientific and academic freedom may be regulated rather than limited by law. It will be exceptionally difficult to justify limitations of scientific or academic freedom. This is a consequence of the importance of the truth function of scientific and academic freedom.

4. A freedom 'in favour of' third parties Scientific and academic freedom entail many inherent duties for the scientist. Society bestows a duty especially on university scientists to explore sincerely. Scientific or academic freedom is a freedom in favour of third parties, directed at delivering truth, so as to elevate humanity. 'Adequacy for science' demands that the Mertonian norms be upheld. Overall, science is not to benefit only privileged groups or sectors, and must be objective, original and sceptical. On disinterestedness, see the next paragraph.

5. Disinterested science To enable scientists to live up to these duties, society accords them substantial freedom so that they are able to explore and discover. Only that freedom makes possible discovery of 'maximum' truth. Where science becomes instrumental, and freedom is thus limited, truth will rather be restricted to specific purposes. Hence, there is a special need for Weberian or Mertonian science - disinterested, free science. The more disinterested science is to be, the freer it must be.

6. Scientific or academic self-duty In ensuring compliance with scientific and academic duties, far more emphasis should be placed on scientific or academic self-duty than is the case at present. There is an excess of regulated forms of ensuring compliance with duties.

7. Safeguards of academic freedom in universities In universities individual academic freedom needs to be accompanied by institutional autonomy, self-governance, collegiality and tenure. Individual academic freedom, self-governance and collegiality are indispensable components of institutional autonomy.

8. Safeguards of scientific freedom in non-university research institutes Inclusive governance, collegiality and participation must also play a role in notably public nonuniversity research institutes. This would imply making provision for senates and other bodies composed of scientific staff, representation in governing bodies, voting rights, and so on.

9. Private companies, non-university research institutes, and universities A distinction should be drawn between private companies conducting research, non-university research institutes, and universities. The state's power of regulation under the REBSPA will be different for each type of entity. From the perspective of scientific and academic freedom, in view of the different roles of these entities in advancing the truth, protection levels for freedom of enquiry should be the highest in universities, much lower in private companies, and medium-to-high in non-university research institutes. Consequently, the stronger the scientific or academic freedom claims are, the weaker must be the state's power of regulation under the REBSPA. Yet, with regard to private companies, it is important 
that principles of free enterprise be respected. Academic freedom applies in universities only.

10. Framework legislation and the role of the scientific fraternity The adoption of framework legislation is crucial. This must protect scientific and academic freedom. It must safeguard the human dignity of all those exposed to science and it must outline appropriate claims to share in scientific progress. The courts must be competent to enforce the entitlements of individuals in this respect. As regards the organisation of science, legislation should exhibit a procedural character and only a modest level of regulatory 'density'. It should provide a basis for the installation of relevant bodies and structures of science and assign the ultimate competence for regulation and decision making to the scientific fraternity itself, as represented in these bodies and operating within these structures. The courts must be competent to safeguard the constitutionality of the legislation, and ensure that it achieves a balance between positive and negative state obligations under the REBSPA that is 'adequate for science' by duly protecting scientific and academic freedom. The government may not transgress the boundaries of its powers as granted by legislation. Its acts, as well as those of the scientific fraternity, are subject to the courts' review competence in respect of scientific and academic freedom.

11. Role players and limiting the role of government The legislature, therefore, is the structural; the scientific fraternity is the everyday; and the judiciary is the final guardian of the science system. Insofar as pure science is concerned, the role of the government is to focus on financing, providing, encouraging, mediating and supervising. State supervision of universities should reflect a hands-off approach, with the state intervening only where academia is clearly in dereliction of its duties. All state action is subject to judicial control.

12. Peer review The scientific fraternity will have to decide on the exact type or nature of quality control considered 'adequate for science'. Peer review as a form of quality control may never be superimposed by the state. Generally, a reduced role for (traditional) peer review would be beneficial. Other forms of quality control - such as editor review, forms of collaborative verification by the larger scientific community, or even 'no' control - should be allowed to flourish. Quality control must respect scientific and academic freedom. The courts must be granted review competences in this respect.

13. Ethical regulation The extent to which ethics assessments should be considered a suitable instrument in the humanities and social sciences, and also the specificities relating to the establishment of ethics codes and bodies, should be for the scientific fraternity to decide. Self-governance is to guard against institutions abusing ethical regulation to elicit conformity through a disciplinary effect. Ethical indeterminacy may threaten scientific progress. The courts must be competent to ensure that ethical regulation duly respects freedom of enquiry, does not disproportionately undermine scientific progress, is guided by principles of a rational responsibility not to cause harm, and, when inspired by human dignity, only protects human dignity as a human rights (and not a moral) concept. 
14. Intellectual property rights A grace period for research publications needs to safeguard compliance with the novelty requirement of patent law. Ideally, university inventions should immediately be publicly available through a public domain strategy or mandatory non-exclusive and affordable licences to a patent. Generally, overprotection in patent law should be addressed as this inhibits innovation and technology transfer. Extensive limitations and exceptions to copyright protection need to be enacted to guarantee access to scientific knowledge in educational or scientific institutions, libraries and archives. The position of university inventors vis-à-vis their institutions needs to be strengthened. Similarly, the copyright of scientists needs to be strengthened vis-à-vis scientific publishers, universities, research institutions, and - for university scientists - also outside actors holding proprietary interests in research findings.

15. Independent, critical, thinking universities While the entrepreneurial university may legitimately play a supplementary role, it should not be the leitmotif for university development. This should rather be the independent, the critical, the thinking university.

16. Trust, not authoritarianism Scientific or academic freedom is the best guarantor of scientific progress in the interest of society at large. Neoliberalism falsely equates freedom with irresponsibility. The corporate university of neoliberalism is authoritarian, disciplinary and dispossessive. It renders free enquiry impossible, undermines rigorous criticality, and dispossesses the academy of 'its' institutions and its role as immediate guardian of the academic system. Trust should be placed in those most qualified to organise and conduct science. In the light of the concept of 'adequacy for science', those most qualified in this respect are scientists rather than science administrators. Trust in the inherent potential of disinterested, free science urgently needs to be re-established. There must be a move away from the public accountability excesses in the science sector of the past three decades. Only this would be 'adequate for science'.

17. The neoliberal approach to science Neoliberal 'instruments of responsibilisation' in higher education and science constitute financial and managerial attacks on higher education and science. The deliberate underfunding of the sector by states, an excessive focus on competitive funding, the financial dependence of institutions on contract research for government or industry, top-down forms of governance in universities and research institutions, and the conscious adoption of an audit culture for and in these, are not 'adequate for science'.

18. The human rights approach to science From both a human rights and economic perspective, pure science should be subsidised at high levels. The emphasis on competitive funding should be reduced. Appropriate organisational dynamics in this context include autonomy for scientists, a positive organisational culture, low hierarchies, reduced emphasis on evaluation, and (as indicated) trust.

19. Research management as a flawed concept Research management, in many ways, is a flawed concept. It consumes enormous resources, finance-, energy-, and time-wise. It seems not to enhance or accelerate innovation and its transfer, negatively affects the quality of scholarly work and undermines scholarly integrity. It may infringe the scientist's 
absolute freedom lying beyond government or university powers, it poisons the atmosphere of freedom that should prevail in universities and severely constricts critical thought by and in universities.

20. Slow science $\mathbf{v}$ publish or perish There should be a renewed emphasis on 'slow science' as quality science. 'Publish or perish' as a central tool of research management impedes the discovery process, spurs scholarly dishonesty and results in the publication of papers of deteriorating quality.

21. Control of commercial scientific publishers The market power and profit margins of commercial scientific publishers need to be limited. 'Publish or perish' (as indicated) should be terminated, open access publishing models be promoted, not-for-profit university publishers be well subsidised by states, publishers be required to pay for peer review, and (as indicated) far-reaching limitations and exceptions to copyright protection be enacted to guarantee access to scientific knowledge.

22. Reasserting the risk principle The risk principle in science needs to be reasserted. The measures implicated by paragraphs 18 and 20 should thus be implemented. Further, in lieu of performance appraisals of staff there should rather be a constructive dialogue between the university or research institution and the staff member on how the former may better facilitate the scientist's work. Financial and moral over-incentivisation in the science sector should be terminated. By way of example, the instrument of performance- or output-based funding for scientists, apart from compromising scholarly integrity, leads to the avoidance of risk that is crucial for scientific progress.

This article has emphasised that an 'adequate' framework for science should address threats to scientific and academic freedom posed by the current primacy of impact agenda science, peer review, ethical regulation, intellectual property rights, entrepreneurialisation, an accountability excess, staff performance appraisals and the absence of rights of participation in governance for scientific and academic staff. The UNESCO Recommendation on Science and Scientific Researchers of 2017 largely fails to understand the scale of these threats for science. An 'adequate' framework safeguards disinterested science, ensures generous state funding of science, provides a more sincere interpretation of the concept of public accountability, is characterised by a minimum of administrative requirements at all levels, and allows scientists to turn inwards. Martha Nussbaum says that '[w]hen a profession is protected by academic freedom ... it tends to turn inward', adding that ' $[\mathrm{t}] \mathrm{o}$ a large extent that's good'. ${ }^{346}$

The state's role is limited. It cannot determine what should be researched, by whom, for how long, and to which ends. Commercialisation, constant competition for funding and publications, and science that can be bought are anathema to science serving society. These developments destroy scientific integrity. Scientists certainly deserve more trust. They have been taught the ethics of science. Moreover, as explained, for scientists there is only 'the way of intuition'. Given the

\footnotetext{
${ }^{346}$ William D Adams, 'The Worldly Philosopher: Martha C. Nussbaum Talks about the Humanities, Mythmaking, and International Development: The 2017 Jefferson Lecturer in Conversation with NEH Chairman William D. Adams' (2017) 38(2) Humanities 12, 13.
} 
space they need, scientists will come up with solutions to problems that plague society. Indeed, we are on the verge of a wholesale collapse and disintegration of modern science. Hence, pondering the question where all the scientific and academic freedoms have gone, it seems more and more of them are on the graveyards as the flowers in Pete Seeger's song. 